Débora dos Santos Queija

\title{
Avaliação do linfedema cérvico-facial e faringolaríngeo e sua relação com a deglutição após o tratamento para o câncer de cabeça e pescoço
}

Tese apresentada à Faculdade de Medicina da Universidade de São Paulo para obtenção do título de Doutor em Ciências

Programa de Fisiopatologia Experimental

Orientador: Prof. Dr. Rogério Aparecido Dedivitis

São Paulo

2018 
Débora dos Santos Queija

\section{Avaliação do linfedema cérvico-facial e faringolaríngeo e sua relação com a deglutição após o tratamento para o câncer de cabeça e pescoço}

Tese apresentada à Faculdade de Medicina da Universidade de São Paulo para obtenção do título de Doutor em Ciências

Programa de Fisiopatologia Experimental

Orientador: Prof. Dr. Rogério Aparecido Dedivitis

São Paulo

2018 


\section{Dados Internacionais de Catalogação na Publicação (CIP)}

Preparada pela Biblioteca da

Faculdade de Medicina da Universidade de Săo Paulo

@reproduçāo autorizada pelo autor

Queija, Débora dos Santos

Avaliaçăo do linfedema cérvico-facial e

faringolaríngeo e sua relação com a deglutição após o

tratamento para o câncer de cabeça e pescoço / Débora dos Santos Queija. -- São Paulo, 2018.

Tese (doutorado)--Faculdade de Medicina da Universidade de São Paulo.

Programa de Fisiopatologia Experimental.

Orientador: Rogério Aparecido Dedivitis.

Descritores: 1.Linfedema 2. Neoplasias de cabeça e pescoço 3.Esvaziamento cervical 4.Radioterapia

5.Avaliaçăo 6.Face 7.Deglutição

$\mathrm{USP} / \mathrm{FM} / \mathrm{DBD}-294 / 18$

Responsável: Eidi Raquel Franco Abdalla - CRB-8/4901 
Aos meus filhos Lucas e Bianca pela alegria, compreensão, companheirismo e amor.

Aos meus Pais Hélio e Neyde (in memoriam) pelo amor incondicional e exemplo de retidão e fraternidade. 


\section{AGRADECIMENTOS}

Ao Prof. Dr. Rogério A. Dedivitis, amigo querido, parceiro e orientador sem o qual nada disso teria sido possível. Entusiasmo e senso de humor ao tratar sempre com disponibilidade incansável minhas dúvidas e questionamentos.

Ao Prof. Dr. Cláudio Roberto Cernea, Professor Responsável da Disciplina de Cirurgia de Cabeça e Pescoço da Faculdade de Medicina da USP e Coordenador da Comissão Assessora de Pesquisa, pela oportunidade de realizar esse estudo.

À Professora Marcia Dalastra Laurenti coordenadora do programa de Pós-graduação em Fisiopatologia Experimental pela oportunidade de estudo e aprendizado.

Aos pacientes, pela cooperação, confiança e boa vontade muitas vezes em um momento difícil.

Ao Professor Dr. Marco Aurélio Kulcsar, pelo auxílio nas traduções das escalas, pela disponibilidade e gentileza em me atender.

À Dra. Lica Arakawa-Sugueno, grande profisisonal e inspiradora deste trabalho, uma amiga querida que fiz nesta caminhada, por todo apoio e amparo incondicionais. Sua contribuição foi fundamental para que pudesse chegar até aqui!

À fisioterapeuta Bruna Mello Chamma, pela contribuição e disponibilidade na coleta e discussão. Muito mais do que uma colega, mas uma amiga e parceira. 
Ao Dr. Jorge Du Ub Kim pela generosidade, disposição e alegria com que me permitiu acompanhar os seus ambulatórios.

Às fonoaudiólogas Hevely Saray Lima Silveira e Lais Aparecida Nunes pela receptividade e generosidade em partilhar e pelo auxílio na coleta de dados e exames.

Ao Prof. Dr. Leandro Luongo Matos, pela contribuição e auxílio com o tratamento estatístico.

Ao Prof. Dr. André Vicente Guimarães, amigo de tantos anos, por todo apoio, carinho e amizade.

Ao Dr. Mario Augusto Ferrari de Castro, querido amigo, pelo carinho, incentivo, auxílio e amizade incondicionais.

Ao Dr. Elio Gilberto Pfutzenreiter pelo auxílio e boa vontade em contribuir.

À Dra. Andrea Anacleto Ferrari de Castro, querida amiga e parceira de Doutorado pela paciência em dividir angústias e alegrias nesta fase de descobertas.

À equipe da Clínica de Cirurgia de Cabeça e Pescoço de Santos, por todo suporte e disponilibildade.

À Sra. Eidi Raquel Franco Abdalla, pleo cuidado na confecção da ficha catalográfica.

À fonoaudióloga Dra. Juliana Portas, amiga e parceira de sempre, pela generosidade e alegria com que me incentiva e apoia! Sua amizade é um presente especial nesta caminhada!

Às minhas amigas e queridas fonoaudiólogas Maria Cecília Pacheco Morel, Sandra Maria Murat, Dra. Michelle Guimarães, Dra. Ranata Guedes 
Bichuetti, Milene Valente Lopes, Glaucia Mazon, Maria Tereza Pedro, Rosemeire Chaves Rodrigues, Alessandra Sampaio Ferreira pela amizade, o carinho e o alto astral de sempre! Orgulho e alegria em tê-las ao meu lado há tanto tempo.

À Jocely Picado pela disponilibilidade, cuidado e ajuda nas retrotraduções das Escalas e do artigo.

Ao meu querido irmão Paulo, por mais uma vez me atender prontamente quando precisei com todo carinho e atenção!

À minha família, minha força, essência e razão de tudo!

A todos que não citei, mas contribuíram direta, ou indiretamente com este trabalho.

A Deus, pela oportunidade de aprendizado no caminho que escolhi seguir. 
"Os pensadores nos quais todas as estrelas têm orbitas cíclicas não são os mais profundos; quem olha para dentro de si como para um espaço sideral e trás vias lácteas em seu interior, sabe também como são irregulares todas as vias lácteas; elas conduzem ao caos e ao labirinto da existência" Nietzsche 
Esta tese está de acordo com as seguintes normas, em vigor no momento desta publicação:

Referências: adaptado de International Committee of Medical Journals Editors (Vancouver).

Universidade de São Paulo. Faculdade de Medicina. Divisão de Biblioteca e Documentação. Guia de apresentação de dissertações, teses e monografias. Elaborado por Anneliese Carneiro da Cunha, Maria Julia de A. L. Freddi, Maria F. Crestana, Marinalva de Souza Aragão, Suely Campos Cardoso, Valéria Vilhena. 3a ed. São Paulo: Divisão de Biblioteca e Documentação; 2011.' 


\section{SUMÁRIO}

Lista de figuras

Lista de tabelas

Lista de quadros

Lista de abreviaturas

Lista de símbolos

Lista de siglas

Resumo

Sumary

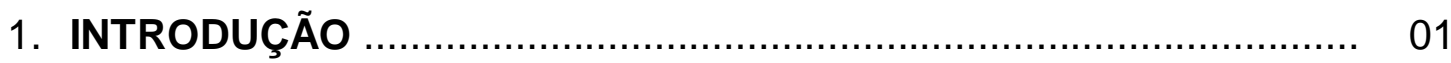

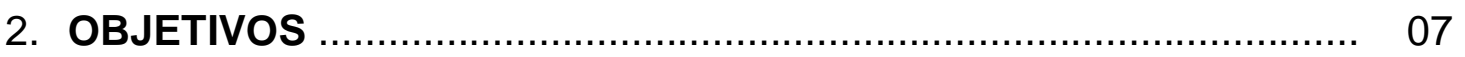

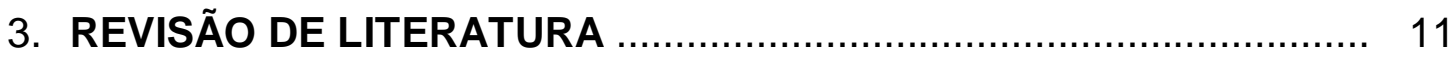

3.1. Tratamento para o câncer de cabeça e pescoço ............................ 13

3.1.2. Edema e linfedema em câncer de cabeça e pescoço .................... 15

3.1.3. Avaliação do edema e do linfedema em câncer de cabeça e

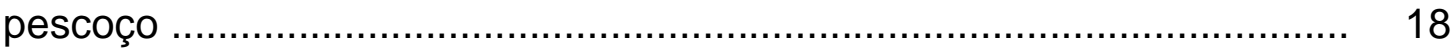

3.1.4. Fatores de risco, prevalência e déficits funcionais relacionados ao edema e linfedema em câncer de cabeça e pescoço ........................... 21

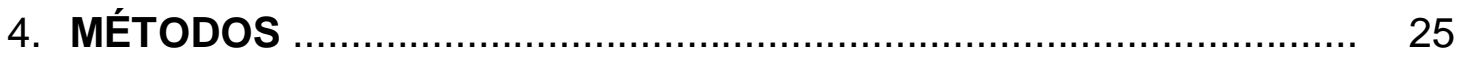

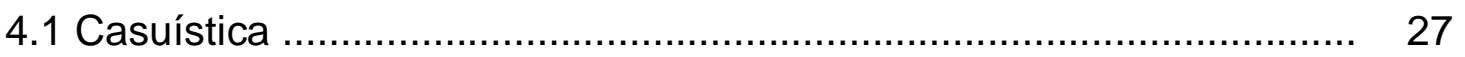

4.1.1 Critérios de inclusão e exclusão ........................................... 27

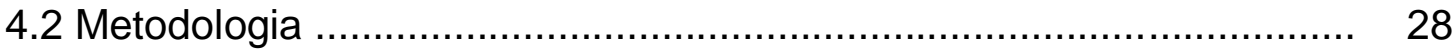

4.2.1 Coleta de dados .............................................................. 28 
4.2.2 Avaliação do linfedema de face ................................................. 29

4.2.3 Avaliação do linfedema cervical ................................................ 29

4.2.4 Estadiamento do linfedema ..................................................... 31

4.2.5 Avaliação do edema de faringe e laringe ..................................... 32

4.2.6 Avaliação videoendoscópica da deglutição …………………........ 34

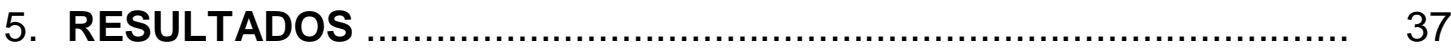

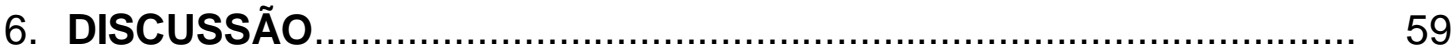

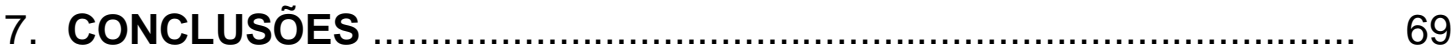

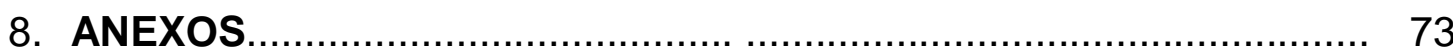

ANEXO A - Aprovação pelo Comitê de Ética em Pesquisa ........................ 75

ANEXO B - Termo de consentimento livre e esclarecido .......................... 76

ANEXO C - Protocolo de avaliação ......................................................... 78

ANEXO D - Avaliação do edema e do linfedema de face e pescoço.......... 79

ANEXO E - Avaliação do edema interno de faringe e laringe .................... 80

ANEXO F - Escala de avaliação de penetração, aspiração e resíduo

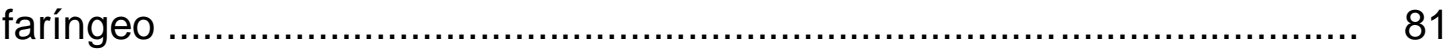

ANEXO G - Medidas da avaliação da face e do pescoço ......................... 82

9. REFERÊNCIAS BIBLIOGRÁFICAS ............................................ 85

$\begin{array}{ll}\text { Apêndice } & 101\end{array}$ 


\section{LISTA DE FIGURAS}

Figura 1 - Avaliação do edema facial e cervical............................................. 30

Figura 2. Extração de medidas para avaliação do edema facial por meio de perimetria adaptada 30

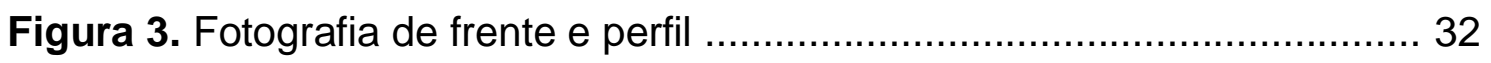

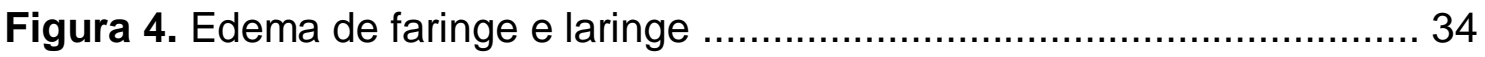




\section{LISTA DE TABELAS}

Tabela 1 Características demográficas, clínicas e do tratamento

Tabela 2 Distribuição da caracterização do linfedema quanto ao local: externo, interno, composto.

Tabela 3 Distribuição do linfedema externo de acordo com a localização e estadiamento pela Escala de linfedema em CCP MDACC

Tabela 4 Distribuição do edema interno de acordo com a Escala do Edema da Radioterapia

Tabela 5 Associação entre a Escala de Penetração e Aspiração (saliva, líquido, néctar, pastoso e sólido) de acordo com a sensibilidade faringolaríngea 50

Tabela 6 Associação entre o edema interno, a Rt e o EC

Tabela 7 Associação entre o edema interno, a deglutição e a sensibilidade faringolaríngea 


\section{LISTA DE ABREVIATURAS}

CCP - Câncer de cabeça e pescoço

Rt- Radioterapia

Qt- Qumioterapia

RtQt- Radio-quimioterapia

EC - Esvaziamento cervical

et al. - e outros

QV- Qualidade de vida

P - Pacientes

$\mathrm{N}$ - Número

1a Diagonal: mento à glabela

1b Submentoniana: $<1 \mathrm{~cm}$ à frente da orelha, alinhamento vertical da fita

2a: Ângulo a ângulo da mandíbula

2b: Trágus a trágus

D - Direito

E- Esquerdo

$\mathrm{Cl}$ - Trágus à protuberância mentoniana

CII - Trágus à comissura labial

CIII - Ângulo da mandíbula à asa nasal

CIV - Ângulo da mandíbula ao canto interno do olho

CV- Ângulo da mandíbula ao canto externo do olho

CVI - Protuberância mentoniana ao canto interno do olho

CVII - Ângulo da mandíbula à protuberância mentoniana

D - Direita 
E - Esquerda

BL - Base de língua

PPF - Parede posterior de faringe

E - Epiglote

PFE - Pregas faringoepiglóticas

PAE - Pregas ariepiglóticas

El - Espaço interaritenóideo

ARC - Área retrocricóidea

A - Aritenóides

PVE - Pregas vestibulares

PV - Pregas vocais

CA - Comissura anterior

V - Valécula

SP - Seios piriformes 


\section{LISTA DE SIGLAS}

ACM - American Cancer Society

MDACC - MD Anderson Cancer Center

HNL - Head and Neck Lymphedema

CTCAE - Common Terminology Criteria for Adverse Events

FCM - Functional Communication Measurements

NOMS - National Outcomes measurements Sistem

VHNSS - Vanderbilt and Head Neck Symptom Survey 


\section{RESUMO}

Queija DS. Avaliação do edema cérvico-facial e faringolaríngeo e sua relação com a deglutição após o tratamento para o câncer de cabeça e pescoço [tese]. São Paulo: Faculdade de Medicina, Universidade de São Paulo; 2018.

INTRODUÇÃO: O tratamento para o câncer de cabeça e pescoço (CCP) envolve várias estruturas e tecido linfático que estão sob risco de prejuízo pelo tratamento cirúrgico e/ou radio-quimioterápico. O linfedema secundário externo e interno de cabeça e pescoço é sequela importante, ainda que subdiagnosticada, subtratada e subvalorizada e, em muitos casos, com impacto nas funções de respiração, deglutição e voz. OBJETIVO: Avaliar a presença, estadiamento e características do edema facial, cervical e laríngeo, a deglutição, após o tratamento para o câncer de cabeça e pescoço. MÉTODOS: O estudo utilizou as Escalas do MD Anderson Cancer Center (MDACC) para avaliar e estadiar o linfedema externo de face e pescoço e a Escala do Edema da Radioterapia de Patterson et al. para o edema interno faringolaríngeo após um mínimo de três meses de tratamento para o CCP, no Serviço de Cirurgia de Cabeça e Pescoço do Hospital das Clínicas da FMUSP e do ICESP. A deglutição foi avaliada por meio de videoendoscopia da deglutição (VED) nas consistências de líquido, néctar, pastoso e sólido. RESULTADOS: O linfedema foi detectado em $97,8 \%$ das avaliações com predomínio do tipo composto $(73,9 \%)$. Foram detectados percentual alto de linfedema externo de pescoço $(71,7 \%)$ e submandibular (63\%), com predomínio para os níveis mais avançados (2 e 3) indicando tendência à fibrose. Encontrou-se edema interno em quase todas as estruturas e espaços avaliados. À VED, observou-se 
resíduo, penetração em todas as cosnistências analisadas. $O$ tratamento combinado com Rt teve relação com o linfedema externo submandibular e pescoço, interno, bem como com a alteração de sensibilidade faringolaríngea, presença de resíduo e penetração para pastoso. CONCLUSÃO: O linfedema cervicofacial e faringolaríngeo é um evento frequente após o tratamento para o CCP, com consequências importantes no desempenho da deglutição caracterizadas por resíduo e levar à penetração e aspiração. $O$ tratamento combinado com Rt é um fator associado a estas alterações.

Descritores: linfedema; neoplasias de cabeça e pescoço; esvaziamento cervical; radioterapia; avaliação; face; deglutição. 


\section{SUMARY}

Queija DS Evaluation of cervicofacial and pharyngolaryngeal lymphedema and its relation to swallowing after treatment for head and neck cancer [thesis]. São Paulo: “Faculdade de Medicina, Universidade de São Paulo"; 2018.

BACKGROUND: Treatment for head and neck cancer (HNC) involves several structures and lymphatic tissue that are at risk of injury by surgical and / or radio-chemotherapy treatment. External and internal secondary lymphedema of the head and neck is an important outcome, although underdiagnosed, undertreated and undervalued, and in many cases with an impact on breathing, swallowing and voice functions. OBJECTIVE: To evaluate the presence, stage and characteristics of facial, cervical and laryngeal lymphedema, swallowing, after treatment for HNC. METHODS: The study used the MD Anderson Cancer Center Scales (MDACC) to evaluate the stage of external face and neck lymphedema and the Patterson et al. for internal pharyngolaryngeal edema after a minimum of three months of treatment for HNC at the Head and Neck Surgery Service of the Hospital das Clínicas of FMUSP and ICESP. Swallowing was evaluated by Fiberoptic Endoscopic Evaluation of Swallowing (FEES) in the consistencies of liquid, nectar, pasty and solid. RESULTS: Lymphedema was detected in $97.8 \%$ of the evaluations with a predominance of the composite type $(73.9 \%)$. A high percentage of external lymphedema of the neck $(71.7 \%)$ and submandibular (63\%) were detected, with a predominance of the more advanced levels (2 and 3 ) indicating a tendency to fibrosis. Internal edema was found in almost all structures and spaces evaluated. At FESS, residue was 
observed, penetration in all analyzed aspects. The combined treatment with Rt was related to external submandibular, neck lymphedema and internal edema, as well as the alteration in pharyngolaryngeal sensitivity, presence of residue and penetration to pasty. CONCLUSION: Cervicofacial and pharyngolaryngeal lymphedema is a frequent event after treatment for $\mathrm{HNC}$, with important consequences on swallowing performance characterized by residue that lead to penetration and aspiration. Combined treatment of Rt is a factor associated with these changes.

Descriptors: lymphedema; head neck neoplasms; neck dissection; radiotherapy; evaluation; face; deglutition 
1 INTRODUÇÃO 



\section{INTRODUÇÃO}

As modalidades de tratamento para o câncer de cabeça e pescoço têm como objetivo o controle da doença e a sobrevivência do paciente. Tanto a abordagem cirúrgica (com ou sem esvaziamento cervical) como a radioterapia exclusiva (Rt), adjuvante à cirurgia ou associada à quimioterapia (Qt) visam, além da cura, a preservação da função das estruturas envolvidas na respiração, voz, deglutição e, dentro do possível, a manutenção da integridade da face e do pescoço do paciente ${ }^{1-3}$. Embora o tratamento aumente as taxas de sobrevida, observa-se um grande risco de o paciente desenvolver sequelas agudas e/ou crônicas, com impacto importante na qualidade de vida ${ }^{4-7}$.

Algumas das complicações inerentes ao tratamento são o edema e o linfedema secundários. A manipulação cirúrgica pode romper as estruturas linfáticas e danificar os tecidos moles adjacentes, levando ao aumento de acúmulo de fluido linfático nos espaços intersticiais. A retenção de fluido linfático ativa respostas inflamatórias e imunológicas, resultando na fibrose dos tecidos moles e subcutâneos, bem como na deposição adiposa, que prejudica a função linfática ${ }^{8,9}$. O edema pós-cirúrgico pode ceder em questão de dias, enquanto o edema causado pelo rompimento da drenagem linfática e vascular pode permanecer e demorar meses para desaparecer. A toxicidade da irradiação também promove danos que levam a alterações durante e após o tratamento, comprometendo os vasos sanguíneos e os canais linfáticos da face e do pescoço, contribuindo para o linfedema $a^{5,10,11}$.

O linfedema pode envolver sítios anatômicos externos (tecidos moles da face e do pescoço) e internos (trato aerodigestório superior, faringe e laringe), 
provocando impacto importante na qualidade de vida do paciente. Além desses dois tipos, pode haver também a combinação de ambos, chamada de linfedema composto 9 .

Como consequência do linfedema externo, podem ocorrer redução da amplitude do movimento, dor e desconforto do pescoço ${ }^{2-6,12}$. O linfedema interno pode comprometer a respiração, a mastigação, a deglutição, a fala e a $v_{0 z}{ }^{8}$. Ambos podem progredir com o decorrer do tempo, mas, quando identificados e tratados precocemente, podem resultar em sua regressão e prevenção dos efeitos tardios, como a fibrose ${ }^{9}$. Portanto, é importante incluir o linfedema como parte da rotina clínica de avaliação do paciente com câncer de cabeça e pescoço ${ }^{13-8}$.

Estudos indicam que $75,3 \%$ dos pacientes evoluem com algum tipo de alteração relacionada ao linfedema no período de três meses ou mais de póstratamento. Destes, 9,8\% têm linfedema externo, 39,4\% linfedema interno e $50,8 \%$ apresentam linfedema composto ${ }^{15,16}$.

Poucas medidas para avaliar o edema o e linfedema foram desenvolvidas ao longo dos últimos anos. A preocupação com esses aspectos vem crescendo na última década, no intuito de identificar e acompanhar a evolução da alteração e os resultados do tratamento ministrado ${ }^{18-23}$. Este interesse inclui a tradução e adaptação para o português brasileiro de duas escalas: a Lymphedema Rating Scale in Head and Neck Cancer que avalia o edema externo e a Escala do Edema da Radioterapia que avalia as estruturas da faringe e laringe $\mathrm{e}^{24,25}$.

À medida que a necessidade de identificar o edema e o linfedema após o tratamento para o câncer de cabeça e pescoço aumentou, surgiram alguns 
questionamentos, como a relação entre as medidas de edema/linfedema externo e interno e a função da deglutição. Ainda não se sabe quais são as características da biomecânica deglutitória no indivíduo com lifedema. Para tal, há necessidade de estudar de forma mais direta estes aspectos. 



\section{OBJETIVOS}





\section{OBJETIVOS}

Mensurar, caracterizar e estadiar a presença do edema de face, pescoço, faringolaríngeo em pontos específicos e correlacionar os achados com a deglutição em pacientes submetidos ao tratamento para o câncer de cabeça e pescoço. 
3. REVISÃO DE LITERATURA 



\section{REVISÃO DA LITERATURA}

\subsection{Tratamento para o câncer de cabeça e pescoço}

No Brasil, o Instituto Nacional do Câncer (INCA) aponta para o biênio 2016-2017 cerca 420 mil casos novos de câncer, sendo que cerca de 5\% são de cabeça e pescoço. O tipo mais comum é o carcinoma de células escamosas $^{26-28}$. O tratamento para 0 câncer de cabeça e pescoço envolve terapias multimodais que proporcionam aumento nas taxas de sobrevida, porém, com riscos de complicações $29-32$.

As sequelas da cirurgia podem variar de acordo com a abordagem e tipo de reconstrução, enquanto a Qt sistêmica afeta as células dos tecidos normais e malignas em todo o corpo. A Rt pode abranger a região do tumor e os tecidos adjacentes, mas volumes significativos de tecido normal no trajeto de seu feixe, ainda que relativamente distantes do alvo, podem ser comprometidos. O fato é que as terapias para o câncer são associadas com um largo espectro de efeitos nos tecidos. A frequência e a gravidade aceitáveis desses efeitos secundários dependem da relação risco-benefício esperada da terapêutica e de fatores individuais. A magnitude dessas alterações depende de uma série de aspectos relacionados ao tratamento, ao tumor e ao paciente. As manifestações clínicas variam de acordo com a dose, fração, volume, estadiamento da doença e outros fatores ${ }^{2,29,33,34}$.

A Rt está associada com uma variedade de efeitos colaterais indesejáveis, como alterações nas funções neuromusculares. No caso do CCP, 
estão relacionadas principalmente às funções de deglutição, voz e respiração. Um estudo histopatológico com espécimes de laringe irradiadas (60-66Gy) comparadas às não irradiadas demonstrou mudanças significativas, com redução nas fibras musculares do tireoaritenoideo associada com edema intersticial e atrofia das fibras musculares no grupo submetido à $\mathrm{Rt}^{35}$.

O uso da terapia de radiação por intensidade modulada (IMRT) tem reduzido significativamente os danos nos tecidos normais adjacentes. Entretanto, o controle locorregional geralmente requer esquemas de doses de radiação altamente agressivas para reduzir a repopulação do tumor. Esses programas com doses de 60 a 70Gy resultam em uma rápida acumulação de doses que, por vezes, são muito menos toleráveis ${ }^{36,37}$. A Qt também pode precipitar o entumescimento tecidual, a inflamação, a irritação, a dor e as reações na pele, que podem persistir após o tratamento ${ }^{5}$.

Em muitos casos, o diagnóstico é tardio com comprometimento de linfonodos regionais e necessidade de esvaziamento cervical (EC) e, por vezes, associado à Rt e Qt. Quanto mais invasiva a abordagem, maior o impacto. Entretanto, a conduta apropriada diante das metástases cervicais é um dos aspectos mais importantes do tratamento e no controle da doença ${ }^{38}$. Por isso, cirurgias que evitam a manipulação de estruturas importantes têm sido utilizadas com o intuito de minimizar os riscos de morbidade relacionados ao $\mathrm{EC}^{6,39-41}$.

Alguns estudos analisaram a relação do EC com o sacrifício do nervo acessório, que leva a alterações nos ombros, enquanto alguns autores revelaram resultados referentes ao período perioperatório e à qualidade de 
vida, contudo, poucos investigaram os efeitos do EC na deglutição e no edema e no linfedema ${ }^{42-49}$.

Esses efeitos podem surgir durante e/ou após o final do tratamento, enquanto os tardios, após em período latente de três meses e permenecer por meses ou anos. As reações precoces, por vezes, são reversíveis e, por isso, pouco valorizadas. No entanto, estudos apontam uma associação entre a ocorrência de reações precoces e subsequentes efeitos tardios, portanto, com a necessidade de caracterizá-las para minimizar seu impacto por meio de tratamento precoce $2,9,15,31-4,50-56$.

O tratamento pode acarretar diversas disfunções, como mucosite, xerostomia, odinofagia, dermatite actínica, disfonia, disfagia, náusea, fadiga, disgeusia, estomatite, perda ponderal de peso, edema e linfedema, que podem variar suas manifestações de acordo com o estadiamento da doença, o sítio do tumor, o comprometimento das cadeias linfonodais, o tipo de tratamento empregado e a condição clínica e nutricional do paciente, com impacto importante na qualidade de vida ${ }^{11,15-18,50-62}$.

\subsubsection{Edema e linfedema em câncer de cabeça e pescoço}

A cabeça e o pescoço têm uma extensa rede de canais linfáticos e mais de 300 linfonodos (a terça parte dos linfonodos do corpo) ${ }^{14,63}$. A contração muscular e a compressão dos tecidos moles facilitam o fluxo da linfa por meio dos movimentos ${ }^{14}$. A disfunção linfática ocorre quando estruturas linfáticas ou tecidos moles circundantes são danificados pelo câncer e o seu tratamento, limitando a capacidade do sistema linfático de transportar o volume da linfa 
entregue aos tecidos. O dano a essas estruturas devido ao tumor, à cirurgia ou à radiação resulta em redução do movimento, dificultando, bloqueando ou rompendo fluxo da linfa, resultando no edema dos tecidos moles ${ }^{10,22,61-66}$.

O edema é definido como o aumento do volume dos tecidos devido à sua expansão intersticial. Pode ser proveniente do aumento da pressão capilar devido a um bloqueio venoso local e bloqueio do retorno linfático por processos cirúrgicos, câncer, anormalidade nos vasos linfáticos e trombose venosa ${ }^{67-69}$.

O grau de severidade do edema e o momento de apresentação podem variar de transitório a permanente e persisitir por semanas ou meses. De forma geral, apresenta-se com início gradual, atingindo o pico em sete a dez dias após a cirurgia. Considera-se um edema prolongado aquele que tem uma espessura $\geq 5 \mathrm{~mm}$, visualizado por meio de imagens de tomografia computadorizada ou ressonância magnética em um período superior a 100 $\operatorname{dias}^{70}$.

O linfedema é o acúmulo de fluido linfático e proteínas no espaço intersticial e pode ser primário ou secundário. O linfedema primário pode estar presente desde o nascimento, manifestar-se na puberdade ou ainda na terceira década de vida ${ }^{71}$.

O linfedema secundário geralmente surge em consequência do tratamento para o câncer, do bloqueio das vias linfáticas causado por um tumor, por trauma, feridas grandes ou circunferenciais ou ainda por queimaduras $^{72}$.

O linfedema secundário externo após o CCP é definido como inchaço visível na pele ou nos tecidos moles da cabeça e do pescoço, enquanto o interno é um edema visível na mucosa e no tecido mole subjacente do trato 
aerodigestório superior, enquanto o composto ou combinado é a coexistência de ambos $^{9,15}$.

Por vezes, quando o linfedema desenvolve-se pela primeira vez, o sistema linfático pode ser capaz de reparar ou compensar o dano, resultando em redução ou resolução do inchaço visível no tecido. Se o dano for grave ou nenhuma intervenção for realizada, o fluido linfático rico em proteína acumulado na região pode desencadear uma resposta inflamatória crônica, resultando em um processo fibroesclerótico em que os tecidos fibrosos ou gordurosos podem desenvolver-se ${ }^{8,73}$.

Após o EC, o edema geralmente é um processo imediato e localizado que ocorre em consequência da obstrução da drenagem venosa e linfática por ligadura dos vasos no procedimento ou por compressão mecânica produzida por hematomas e pode exibir duas fases ${ }^{74}$. De início, há um desequilíbrio entre a filtragem e a evacuação pelo aumento do aporte líquido filtrado, não ocorrendo o mesmo com o sistema de drenagem. Dessa forma, os tecidos enchem-se de líquido e a pressão intersticial aumenta, havendo distenção da pele. Posteriormente, quando a rede de evacuação é insuficiente, causada pela ressecção dos linfonodos, o edema instala-se e organiza-se, predispondo à formação de tecido fibroso (linfedema), tornando as possibilidades de evacuação diretamente relacionadas ao grau de evolução e de organização $0^{75}$.

A alteração linfática torna o tecido linfático incapaz de transportar quantidades normais de fluido e proteína da filtragem capilar normal, razão pela qual ocorre o linfedema pós-CCP 5,14 . 


\subsubsection{Avaliação do edema e do linfedema em câncer de cabeça e pescoço}

Vários critérios e ferramentas de classificação clínica foram desenvolvidos para avaliar o edema e o linfedema externo da pele e dos tecidos moles. Esses critérios podem ser classificados como gerais, quando aplicados a todas as partes do corpo ou específicos - pertinentes à região da cabeça e do pescoço. De forma geral, todos têm em comum a descrição da apresentação do tecido. Portanto, há a necessidade de conhecimento desse tipo de alteração para que a caracterização seja equivalente à manifestação propriamente dita ${ }^{14}$.

As escalas de classificação geral mais comumentes usadas são a Escala de Földi e a CTCAE Lymphedema-Related Fibrosis Scale (versão 3.0) (CTCAE Fibrosis Scale). Cada uma delas usa diferentes descritores e diversos componentes ${ }^{14,20,76}$.

Para as estruturas da cabeça e pescoço, as ferramentas são a Common Terminology Criteria for Adverse Events (CTCAE) Lymphedema Scale Head and Neck (versão 3.0 - CTCAE Lymphedema Scale) do National Cancer Institute $(\mathrm{NCl})^{77}$ e a da American Cancer Society Scale (ACS), denominada Lymphedema of the Head and Neck Scale ${ }^{75}$. Todavia, nenhuma dessas escalas foi validada e houve dificuldade em capturar características importantes do linfedema externo e nenhuma delas capta o edema e a fibrose que coexiste em alguns pacientes ${ }^{14,20}$.

Um estudo analisou as quatro escalas simultaneamente, examinando as diferenças nos achados baseados em cada uma delas e identificou a lacuna na 
avaliação do linfedema externo em um grupo de pacientes com CCP com três meses ou mais de término do tratamento. Os autores concluíram ainda não haver uma ferramenta que capturasse todas as características importantes referentes ao linfedema pós-CCP20.

Outra ferramenta foi criada pelo grupo do MD Anderson, denominada M.D. Anderson Cancer Center (MDACC HNL) Head and Neck Lymphedema Rating Scale. O estadiamento é baseado na caracterização do estado da pele e na apresentação do tecido, levando em consideração a reversibilidade, a firmeza e o inchaço. Além disso, há uma classificação do edema da face e do pescoço em uma escala com extração de medidas em pontos anatômicos da face e do pescoço (ponto a ponto bilaterais) por meio de perimetria ${ }^{18,19,24,76}$.

Outra forma de mensurar por meio de um dispositivo que contém uma sonda para a extração da constante dielétrica (Moisture MeterD) do tecido foi desenvolvida e aprimorada com a capacidade de mensurar mudanças locais de água na pele e gordura subcutânea em qualquer local do corpo humano ${ }^{71,77}$.

Um protocolo foi elaborado com algumas medidas de avaliação do linfedema em CCP $(A L O H A)$. A ferramenta consiste de medidas de perimetria das circunferências superior e inferior do pescoço, orelha a orelha e da extensão do lábio até a circunferência inferior do pescoço (borda do lábio inferior até a circunferência inferior do pescoço). Além dessas ferramentas, foi usado um instrumento para avaliar o conteúdo da água tecidual da face e do pescoço (Moisture MeterD) por meio de uma sonda. O estudo indicou uma fraca confiabilidade nas medidas extraídas da extensão do lábio à circunferência inferior do pescoço, enquanto a comparação entre a escala de estadiamento e a constante dielétrica do tecido obteve boa confiabilidade. As 
medidas de perimetria foram úteis para avaliar as mudanças do tecido ao longo do tempo e o Moisture MeterD para diagnosticar o linfedema ${ }^{78}$.

De forma geral, as escalas que lançam mão do registro de medidas usam como base a perimetria adaptada com a trena antropométrica e o registro em fotografia de frente e perfil para avaliar o edema e o linfedema ao longo do tempo $14,19,78,79,81$.

Técnicas de imagem como a ressonância magnética e a tomografia computadorizada fornecem dados precisos das mudanças de valores do edema, porém, são recursos de alto custo (ressonância magnética) e submetem o paciente ao risco de sucessivas exposições à radiação (tomografia computadorizada) e ao constraste intravenoso. A ultrassonografia pode ser usada, com ressalvas à ecogenicidade de suas imagens, muitas vezes não específicas, para alterações na água da pele. Para a face, a medida ecográfica parece não refletir o local mais edemaciado pelas distâncias de pele até o osso causando certa desproporcionalidade em alguns casos ${ }^{79}$.

Recentemente, outra escala foi desenvolvida pela necessidade de capturar as diferenças dos tecidos e contemplar aspectos referentes às mudanças do tecido tanto no edema e linfedema até a fibrose. Os autores alegam que alguns pacientes podem desenvolver exclusivamente a fibrose, ao passo que outros podem evoluir com linfedema e fibrose simultaneamente e outros, o linfedema típico. O fato é que o linfedema e a fibrose podem coexistir, ainda que em sítios diferentes (por exemplo, linfedema de face e fibrose no pescoço). Embora os dois mecanismos sejam diferentes, eles podem ter componentes inflamatórios em comum. A fibrose pode contribuir para a disfunção do sistema linfático e agravar o linfedema e este progredir para a 
fibrose. Por essa razão, é importante caracterizar as diferenças teciduais para que o tratamento seja precoce e mais profícuo ${ }^{12}$. A ferramenta foi aplicada em um estudo recente e comparada ao exame de ultrassonografia. Os achados demonstraram boa confiabilidade e que captura de forma válida as mudanças dos tecidos moles em locais selecionados ${ }^{21}$.

A Radiotherapy Edema Rating Scale, desenvolvida por Patterson et al., é a ferramenta mais abrangente que avalia e gradua o edema e o linfedema interno de forma simples e objetiva 11 estruturas e dois espaços da faringe e da laringe por meio de endoscopia. A escala teve boa confiabilidade intraavaliadores $($ Kappa $=0,84)$ e moderada inter-avaliadores $(\text { Kappa }=0.54)^{82} . \quad O$ instrumento foi usado em vários estudos ${ }^{14,21,83-86}$.

\subsubsection{Fatores de risco, prevalência e déficits funcionais relacionados ao edema e linfedema em CCP}

Há uma grande variedade demonstrada na literatura a respeito da prevalência estimada de linfedema em CCP. Esse fato pode estar relacionado tanto à diversidade de sítios anatômicos da região do linfedema, quer seja externo ou interno, quanto pelo período de acompanhamento do estudo, às diferenças nos critérios de avaliação e de regimes de tratamento ${ }^{9,15}$.

Estudos da década passada referiam a ocorrência de linfedema

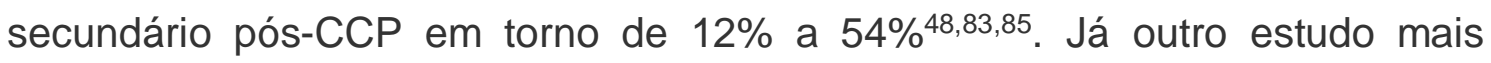
recente, com 81 pacientes de vários sítios e formas de tratamento em um período médio de 24,7 meses após seu término, apontou algum tipo de linfedema em $75 \%$ dos pacientes. Deste grupo, $50,8 \%$ foi identificado com 
linfedema composto, 39,4\% interno e 9,8\% externo. Dos 37 pacientes com linfedema externo, $64,9 \%$ eram restritos à região do pescoço, enquanto $27 \%$ eram na face e pescoço e somente $8 \%$ na face, pecoço e olhos. Quanto ao estadiamento, houve predomínio do estágio II, segundo a Escala de Földi $(27,2 \%)$. O linfedema interno de grau moderado foi identificado em $45,5 \%$ dos exames seguido de $34,5 \%$ discreto e $20 \%$ severo. A região submentoniana foi a mais acometida pelo linfedema externo e o espaço interaritenoideo pelo linfedema interno de grau moderado e severo ${ }^{15}$.

A prevalência do edema facial prolongado pós-CCP e a relação com algumas variáveis clínicas foi investigada por Chen et al. Os autores não encontraram associação entre a modalidade de tratamento (cirurgia e RtQt pós-operatória, RtQt primária, Qt ou cirurgia exlcusivas) e concluíram que o edema facial não está relacionado ao tipo de tratamento empregado. Entretanto, o EC foi significativamente associado ao edema facial tardio ${ }^{70}$.

Mozzini avaliou a relação entre o EC com ou sem a ressecção da veia jugular interna e o linfedema em 51 pacientes pós-CCP. Observou que não houve diferença entre os dois grupos, contudo, houve diferença entre o pré e o pós-operatório em cada grupo, independente da preservação ou não da veia, sendo os pontos mais afetados a região mandibular e do pescoço ${ }^{73}$.

Segundo estudo recente, o número de modalidades de tratamento é referido como fator associado ao aumento da probabilidade da presença de todos os tipos de linfedema. Os tumores de faringe são os mais propensos à evolução de linfedema externo e combinado que os outros sítios. A dose total e o número de dias de radiação estão associados com a possibilidade de linfedema composto e a radiação do leito cirúrgico com o linfedema interno9 ${ }^{\text {. }}$ 
Ridner et al. acompanharam 83 pacientes com CCP submetidos à Rt associada ou não à Qt e/ou cirurgia para verificar a presença de linfedema interno, externo e da fibrose como um fenômeno contínuo. Para tal, iniciaram o seguimento antes do início da radioterapia e mantiveram o acompanhamento no pós-tratamento nos perídos de três a seis meses, nove meses, 12 meses e $>12$ meses. Os resultados demonstraram que $82 \%$ tinham algum tipo de linfedema externo após mais de ano de término do tratamento, sendo $46,8 \%$ de grau moderado a severo e o linfedema interno em $80,4 \%$ com $43,2 \%$ de grau moderado a severo. No período mais tardio ( $>12$ meses), a fibrose foi reconhecida em $77 \%$ dos casos, sendo $37 \%$ de grau moderado a alto. Outro ponto importante é que houve uma tendência ao desenvolvimento de fibrose grave nos pacientes com Rt pós-operatória quando comparados à Rt primária. Os autores consideram que a apresentação do déficit funcional tem associação com o sítio do tecido envolvido pelo edema, por exemplo, os casos de pacientes com linfedema ou fibrose faríngea são mais propensos a desenvolver disfagia ao passo que a fibrose no pescoço tem maior relação com a dificuldade na mobilidade cervical e dor musculoesquelética ${ }^{85}$.

Deng et al. investigaram a associação entre o grau do linfedema externo e interno com o fardo do sintoma, a condição funcional e a qualidade de vida $(\mathrm{QV})$ pós-CCP. Constataram que a severidade do linfedema externo foi associada com o relato de dificuldade de deglutição, sintomas nutricionais (perda de peso) e de mobilidade cervical (lateral e rotação), enquanto a gravidade do linfedema interno foi relacionada com a autopercepção de sintomas vocais. Os efeitos do grau do linfedema composto apresentaram associação com a queixa de redução da audição ${ }^{16}$. 
Jackson et al. buscaram estabelecer uma relação entre o linfedema externo e interno e medidas deglutição em um período de 13 semanas a 18 meses após o término do tratamento. A deglutição foi avaliada por meio da videofluoroscopia, pela Functional communication measures - FCM pertencentes à National Outcomes measurements Sistem - NOMS que contém sete níveis (1 - inabilidade para deglutir e 7 - totalmente independente, não limitada pela função de deglutição) e pelo questionário Vanderbilt and Head Neck Symptom Survey (VHNSS) na versão 2.0, que inclui 13 questões relacionadas à deglutição e nutrição (em três grupos: deglutição de sólidos, líquidos e nutrição). Os resultados apontaram para uma correlação entre as pontuações do questionário, a escala NOMS e avaliação objetiva da deglutição. Forte associação foi observada entre a escala NOMS, o questionário e o grau máximo de inchaço em alguma estrutura interna avaliada pela escala de Patterson. O linfedema interno de pregas ariepiglóticas, epiglote, recessos piriformes foram fortemente associados com os itens de nutrição e deglutição do questionário VHNSS e a escala NOMS ${ }^{86}$.

É importante considerar que o linfedema é um fenômeno clínico que tem um potencial importante de causar uma carga significativa dos sintomas e perda da função ${ }^{15}$. Há a necessidade de caracterizar precocemente para compreendê-lo e tratá-lo. 
4 MÉTODOS 



\section{MÉTODOS}

\subsection{Casuística}

Trata-se de um estudo transversal prospectivo aprovado pelo Comitê de Ética em Pesquisa da Faculdade de Medicina da Universidade de São Paulo sob o número 137/14 (Anexo 1). Todos os indivíduos foram consultados sobre o interesse em participar do referido estudo e orientados previamente quanto aos detalhes deste e preencheram o Termo de Consentimento Livre e Esclarecido (Anexo 2).

Foram avaliados o edema externo, interno e a deglutição de pacientes tratados por CCP no Hospital das Clínicas da Faculdade de Medicina da Universidade de São Paulo e no Instituto do Câncer do Estado de São Paulo ICESP, São Paulo.

\subsubsection{Critérios de inclusão e de exclusão}

Critérios de inclusão

- Diagnóstico histológico de carcinoma de células escamosas das vias aerodigestórias superiores confirmado;

- Pacientes submetidos ao tratamento cirúrgico com ou sem reconstrução para câncer de cavidade oral, orofaringe, laringe, hipofaringe e rinofaringe, com ou sem esvaziamento cervical; ou pacientes submetidos à radioterapia associada ou não à quimioterapia e/ou cirurgia; 
- Pacientes submetidos às ressecções cirúrgicas para tratamento de câncer avançados de tireoide, glândula parótida que necessitassem de EC;

- Período mínimo de término do tratamento de três meses.

Critérios de exclusão

- Laringectomia total;

- Linfedema crônico (anterior ao tratamento);

- Paciente sem condições clínicas no momento da realização dos exames;

- Paciente incapaz de realizar alguma das avaliações do estudo.

\subsection{Metodologia}

\subsubsection{Coleta de dados}

A coleta de dados foi preenchida a partir do prontuário do paciente e a complementação na entrevista de avaliação pertencente ao protocolo de avaliação com informações referentes à identificação, dados do tumor (sítio, TNM) e do tratamento (tipo de tratamento, dose, tempo de término), presença de sonda e traqueostomia, forma de alimentação e alguns sintomas. (Anexo C)

Os pacientes recrutados para o estudo tinham um período mínimo de três meses de término do tratamento.

O exame do edema externo e interno combinou registro em foto e vídeo, gravação de medidas e estadiamento de edema para caracterizar a aparência global e a sua respectiva severidade. 


\subsubsection{Avaliação do linfedema de face}

O protocolo contém avaliação visual e tátil da face. Para a avaliação visual, a face do paciente foi demarcada com caneta antialérgica para a mensuração bilateral das proporções faciais por meio de perimetria adaptada (trena antropométrica) de acordo com os critérios adotados por Smith et al. na Escala traduzida e adaptada para o português brasileiro que contêm duas medidas da circunferência facial (diagonal e submentoniana) ponto a ponto e

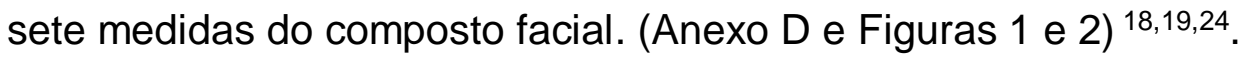

\subsubsection{Avaliação do linfedema cervical}

O diâmetro do pescoço do paciente foi mensurado por meio de perimetria da circunferência (trena antropométrica) que extrai as medidas superior, medial e inferior do pescoço e fornece a pontuação do composto do pescoço ${ }^{18,19,24}$. (Anexo D, Figuras 1 e 2). 
Figura 1. Avaliação do edema facial e cervical. Os números correspondem às setes medidas da composição facial e as letras às três medidas da "Escala composta do pescoço". Foto autorizada pelo paciente.

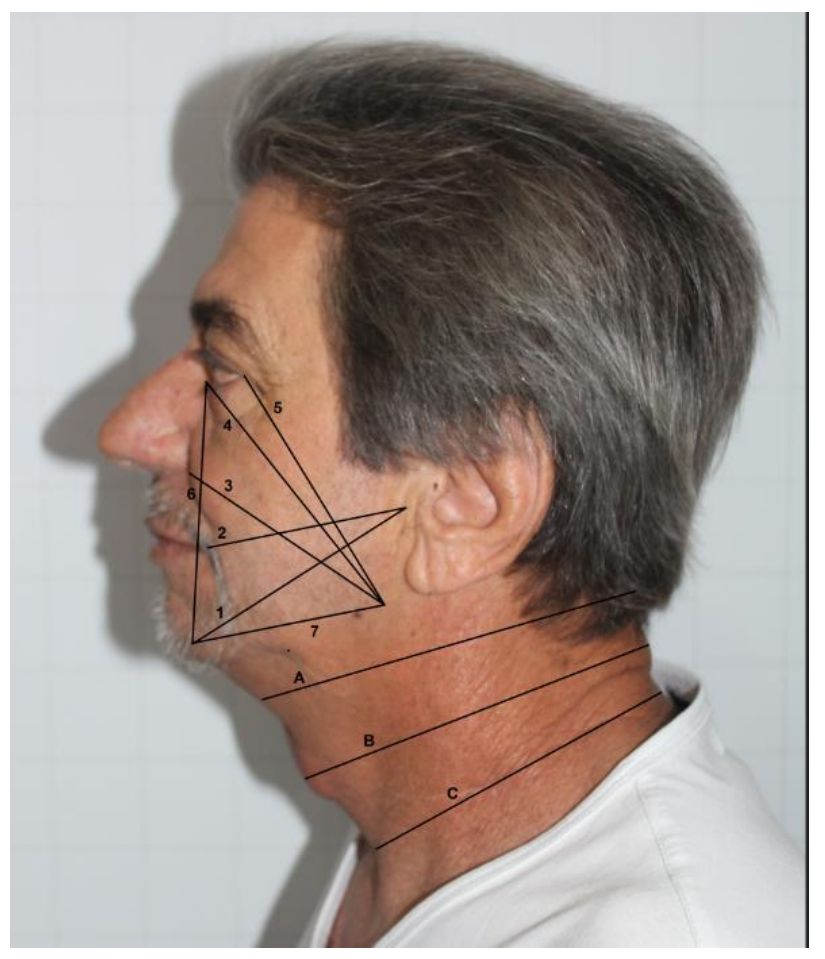

Figura 2. Extração de medidas para avaliação do edema facial por meio de perimetria adaptada. Foto autorizada pelo paciente.

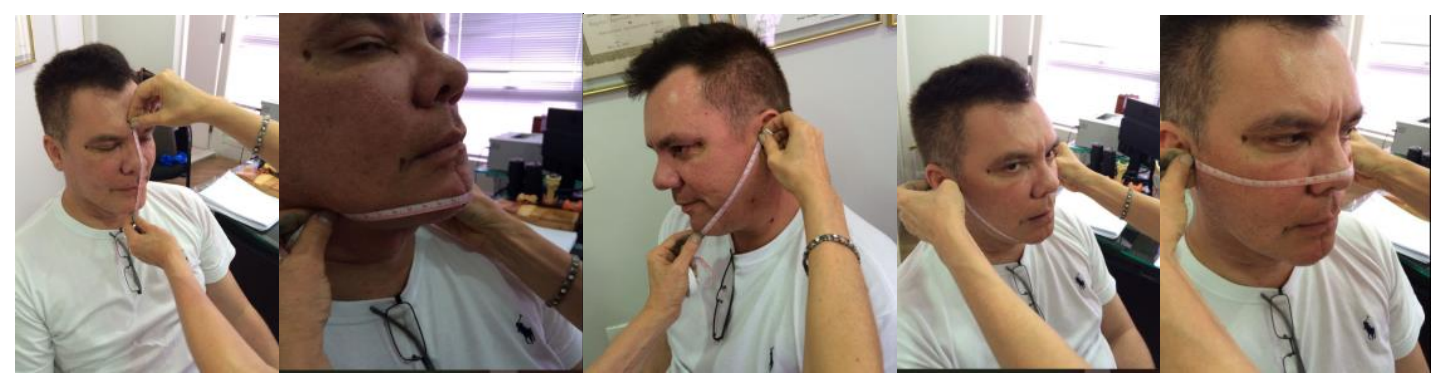




\subsubsection{Estadiamento do linfedema}

A Escala de Estadiamento do Linfedema (Anexo D) foi criada para caracterizar a apresentação e a gravidade do edema em câncer de cabeça e pescoço e é baseada na tradicional Escala de Földi para o estadiamento do linfedema de extremidades. Na Escala adaptada do MDACC, o nível 1 foi dividido em 1a e 1b para delinear o edema em depressível e não depressível ${ }^{19,24}$. Nesse caso, a avaliação faz-se por meio de pressão digital na pele da área do edema, que indica a presença de fluido intersticial na região. A pressão foi exercida de forma leve na área avaliada por um período de 10 segundos. O edema é depressível quando se identifica a permanência do recuo do tecido após a pressão digital. A profundidade da depressão do tecido e o tempo de permanência deste refletem a gravidade do edema. O edema depressível é mais mole, enquanto o edema não depressível é mais rígido e não cede com a pressão22 (Anexo D, Quadro 1).

O registro fotográfico foi realizado e a câmera posicionada sob um tripé sempre na mesma posição. Todos os pacientes foram fotografados, tendo como pano de fundo um quadro quadriculado, com o paciente em pé, nas posições de frente e perfil com câmera Canon EOS T4i, com objetiva de 18$55 \mathrm{~mm}$. (Figura 3) 
Figura 3. Fotografia de frente e perfil.

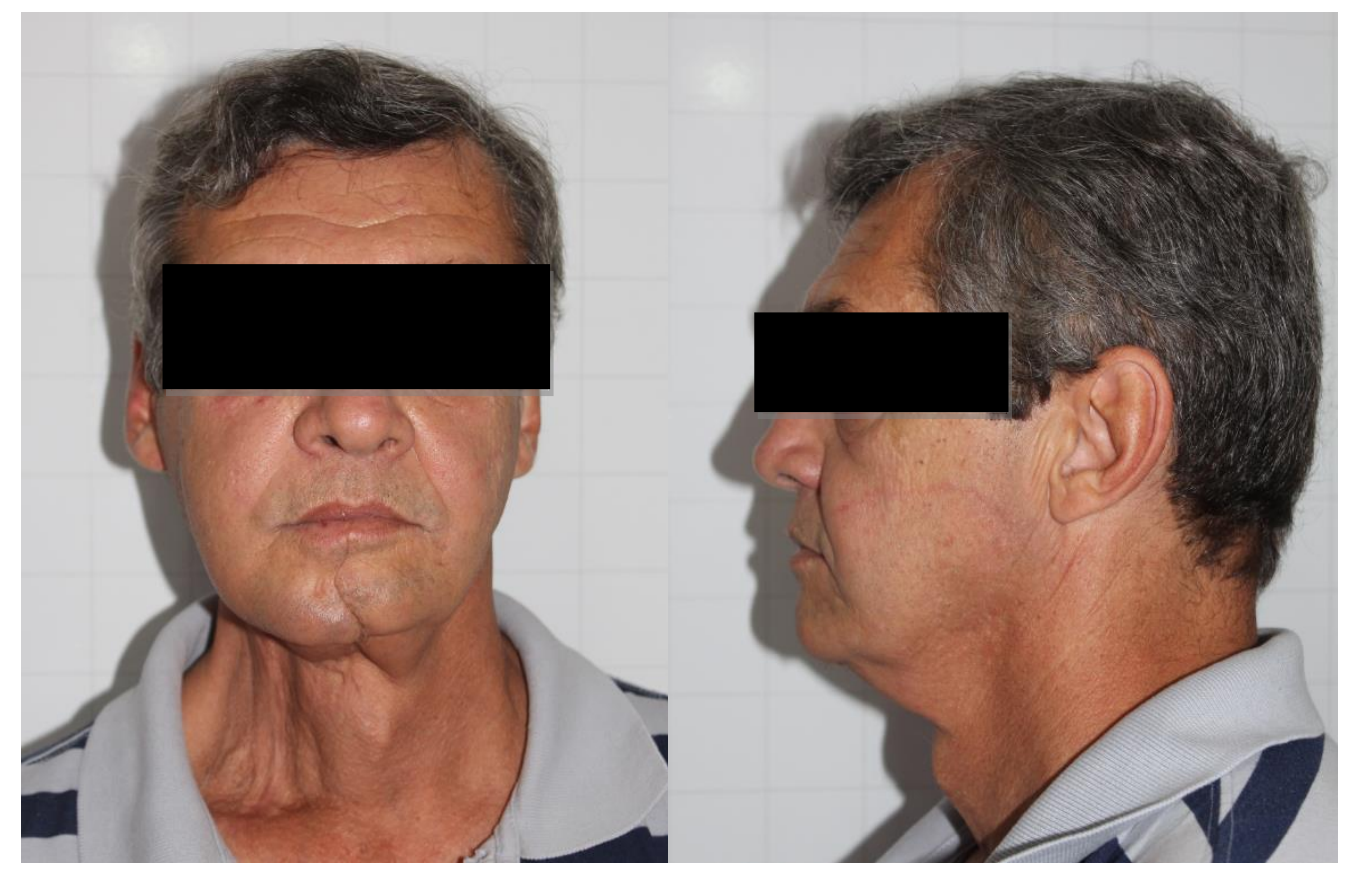

\subsubsection{Avaliação do edema de faringe e laringe}

Para a realização do exame de avaliação do edema faringolaríngeo, o paciente foi orientado a permanecer sentado, com região cervical em posição de leve ventro-flexão. Os exames foram realizados por um médico cirurgião de cabeça e pescoço e o aparelho de fibroscópio foi introduzido pela fossa nasal mais ampla do indivíduo, sem a utilização de anestesia tópica, para não interferir na sensibilidade faringo-laríngea. Utilizou-se os equipamentos:

- Nasofibroscópio da marca Welch-Allym;

- Fonte de luz do estroboscópio Kay Elemetrics® modelo RLS 9100 B;

- Microcâmera Toshiba CCD IK-M41A;

- Monitor de vídeo Sony KV-1311 CR. 
Para a identificação do edema faringolaríngeo, foram utilizados os critérios da Escala do Edema da Radioterapia de Patterson et al. traduzido e adaptado para o português brasileiro, que faz a classificação de acordo com o grau: normal - ausência de edema, edema discreto, moderado ou grave e so espaços como normal, discretamente reduzido, moderadamente reduzido e severamente reduzido ${ }^{23,25}$ (Anexo E, Quadro 2 - Apêndice, Figura 4).

A sensibilidade faringolaríngea foi avaliada observando-se a resposta ao toque sutil da ponta do nasofibroscópio na região de aritenóides e a presença ou ausência do reflexo de adução e/ou tosse.

O exame de videoendoscopia da deglutição foi realizado na sequência. O exame foi gravado em DVD e, posteriormente, analisado por dois médicos cirurgiões de cabeça e pescoço e uma fonoaudióloga em consenso. 
Figura 4: Edema de faringe e laringe: A- ausência de edema; B- edema discreto; C- edema moderado; D- edema grave

A

B

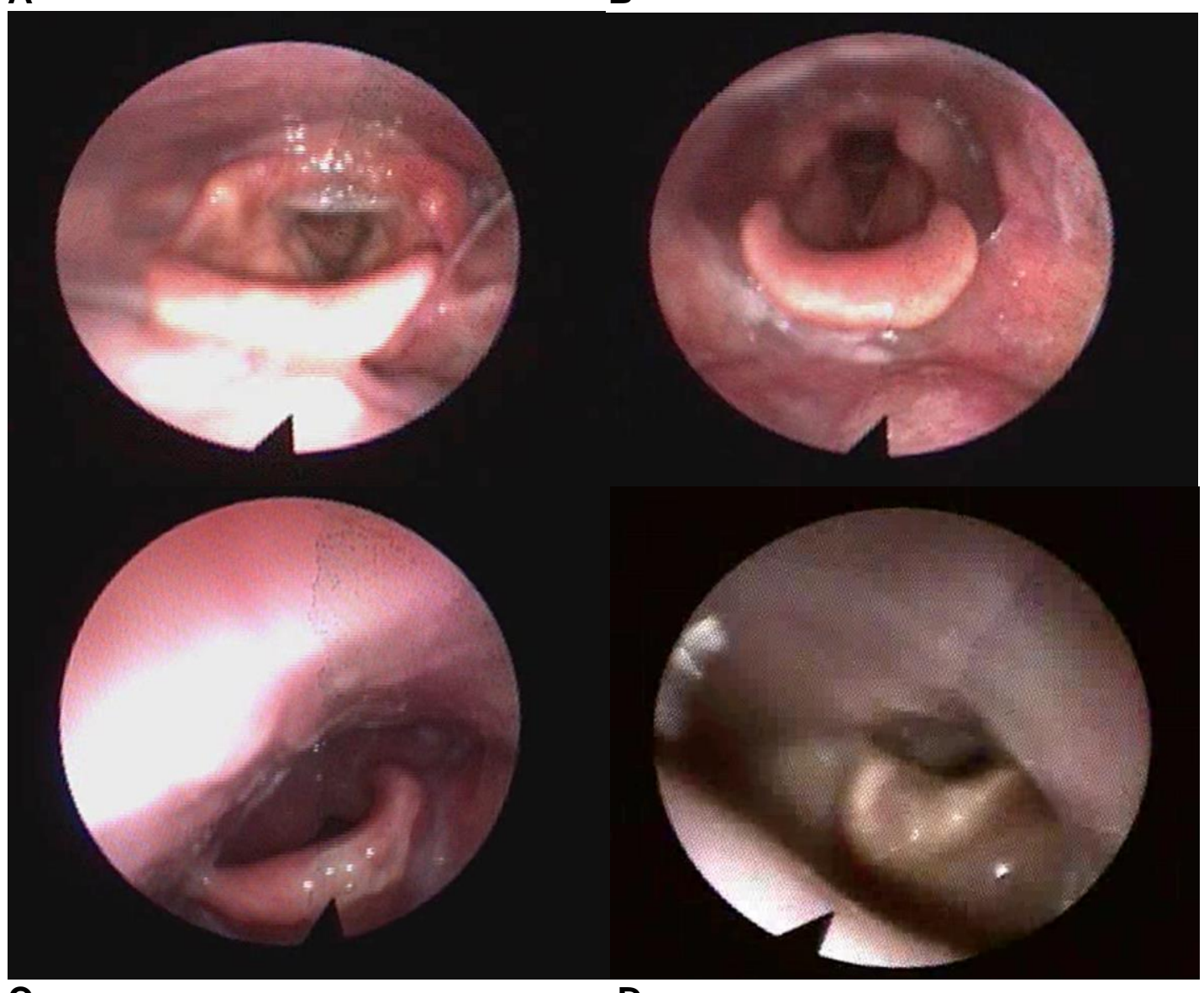

C D

\subsubsection{Avaliação videoendoscópica da deglutição}

Para a análise da VED, foi dado seguimento ao exame com oferta de quatro consistências líquido, néctar, pastoso e sólido coradas de anilina azul líquida da marca Arcólor e preparadas de acordo com a textura com o espessante da marca Resource ${ }^{\circledR}$ ThickenUp Clear. As quantidades oferecidas foram $5 \mathrm{~mL}$ e $10 \mathrm{~mL}$ de suco de laranja no copo de café $(50 \mathrm{~mL})$ ou na colher de $5 \mathrm{~mL}$ nas consistências mais espessas. Apesar de não ser a 
quantidade oferecida aos pacientes, para atingir cada consistência, usamos as seguintes proporções entre o espessante e o suco: para testar o néctar foi usada uma receita de uma medida para $100 \mathrm{~mL}$ de suco e três medidas para pastoso. Para a textura sólida, foi oferecido um pedaço de pão de aproximadamente $1,5 \times 1,5 \mathrm{~cm}$.

Os itens avaliados no protocolo de deglutição foram: perda prematura, de alimento, penetração, aspiração, presença de resíduos em: base de língua, valécula, parede posterior de faringe e seios piriformes. Para quantificar e caracterizar o grau de estase, foi usada a Escala modicada de Rosenbek et al. ${ }^{87}$ por Jung et al. ${ }^{88} \mathrm{e}$, para a severidade da penetração e aspiração, foi usada a Escala de Penetração e Aspiração de Rosenbek (Anexo E, Quadros 3 e 4). A análise foi realizada a partir das deglutições de saliva e de cada consistência oferecida. Se o paciente tinha restrição para alguma textura, optou-se por respeitar a limitação.

Os dados foram gravados em DVD e analisados por duas fonoaudiólogas em consenso identificando os itens do protocolo.

Para auxiliar a análise os dados relativos ao grau do edema interno, optou-se por agrupá-los de acordo com a classificação de moderado e severo para moderado/severo.

Para comparar as variáveis com as demais categorias, optou-se por agrupar o tratamento em dois: A - Rt dividido em: 1) não Rt: todo tratamento em que não foi realizada a Rt, 2) Rt: Cirurgia + Rt, Cirurgia + Rt + Qt, Rt-Qt e Rt exclusiva; B - EC dividido em 1) não EC; 2) EC. 
Mais duas variáveis foram comparadas aos outros aspectos analisados: sensibilidade faringolaríngea que foi interpretada: 1) preservada, 2) alterada; resíduo/estase para qualquer das consistências testadas: 1) não, 2) sim.

A distribuição de frequências foi utilizada para descrever as variáveis categóricas e as medidas de tendência central (média e mediana) e de variabilidade (mínimo, máximo e desvio padrão) para as numéricas. Para comparar as variáveis categóricas em relação tratamento Rt (não/sim) resíduo/estade (não/sim), sensibilidade faringolaríngea (não/sim) e EC (não/sim) em tabelas de contingência o teste de frequências do qui-quadrado foi utilizado e em tabelas $2 \times 2$ quando pelo menos uma frequência esperada foi menor do que 5 o teste exato de Fisher foi adotado. O nível de significância de $5 \%$ foi adotado para todos os testes estatísticos. O programa STATA versão 10.0 foi utilizado para a realização das análises estatísticas ${ }^{89}$. 
5 RESULTADOS ‘ 



\section{RESULTADOS}

A amostra contou com 46 pacientes com diagnóstico de CCP, avaliados no período de janeiro de 2016 a janeiro de 2018, selecionados no Ambulatório do Serviço de Cirurgia de Cabeça e Pescoço do Hospital das Clínicas da Faculdade de Medicina da Universidade de São Paulo e no Instituto do Câncer do Estado de São Paulo - ICESP, São Paulo.

Os sítios predominantes foram boca $(28,3 \%)$ e orofaringe $(23,9 \%)$. Quanto ao tipo de tratamento, 32 pacientes $(69,6 \%)$ foram tratados por meio de cirurgia. O EC cervical foi realizado em $59,7 \%$, sendo que $28,3 \%$ destes foram do tipo supraomoioideo. A Tabela 1 descreve as características demográficas, clínicas e de tratamento.

Tabela 1 - Características demográficas, clínicas e de tratamento.

\begin{tabular}{llc}
\hline Variável & Categoria / Medidas & Freq. (\%) / Medidas \\
\hline Idade & Variação & $29-82$ \\
& Mediana & 61 \\
Gênero & Média \pm desvio padrão & $61,2 \pm 11,5$ \\
& Feminino & $13(28,3)$ \\
Raça & Masculino & $33(71,7)$ \\
& Caucasiana & $42(91,3)$ \\
Etilismo & Afrodescendente & $4(8,7)$ \\
& Não & $44(95,6)$ \\
& Sim & $2(4,4)$
\end{tabular}




\begin{tabular}{|c|c|c|}
\hline Variável & Categoria / Medidas & Freq. (\%) / Medidas \\
\hline \multirow[t]{2}{*}{ Tabagismo } & Não & $42(91,3)$ \\
\hline & Sim & $4(8,7)$ \\
\hline \multirow[t]{8}{*}{ Sitio da doença } & Boca & $13(28,3)$ \\
\hline & Orofaringe & $11(23,9)$ \\
\hline & Rinofaringe & $5(10,9)$ \\
\hline & Laringe & $8(17,4)$ \\
\hline & Primário oculto & $2(4,3)$ \\
\hline & Infraglote & $1(2,2)$ \\
\hline & Tireoide & $4(8,7)$ \\
\hline & Face (pele) & $2(4,3)$ \\
\hline Estadiamento & T0 & $1(2,2)$ \\
\hline \multirow[t]{6}{*}{ clínico T } & $\mathrm{T} 2$ & $21(45,7)$ \\
\hline & T3 & $6(13,0)$ \\
\hline & $\mathrm{T} 4$ & $8(17,4)$ \\
\hline & $\mathrm{TX}$ & $3(6,5)$ \\
\hline & $\mathrm{T} 1 \mathrm{~b}$ & $2(4,3)$ \\
\hline & Não avaliável & $5(10,9)$ \\
\hline Estadiamento & No & $28(60,9)$ \\
\hline \multirow[t]{5}{*}{ clínico N } & N1 & $4(8,7)$ \\
\hline & N2 & $3(6,5)$ \\
\hline & $\mathrm{N} 2 \mathrm{a}$ & $3(6,5)$ \\
\hline & $\mathrm{N} 2 \mathrm{~b}$ & $3(6,5)$ \\
\hline & N2c & $\begin{array}{c}2(4,3) \\
\text { continua } \\
\text { contınuaçao }\end{array}$ \\
\hline
\end{tabular}




\begin{tabular}{|c|c|c|}
\hline Variável & Categoria / Medidas & Freq. (\%) / Medidas \\
\hline & N3 & $2(4,3)$ \\
\hline & N3b & $1(2,2)$ \\
\hline \multirow[t]{2}{*}{ Estadiamento M } & MO & $45(97,8)$ \\
\hline & M1 & $1(2,2)$ \\
\hline \multirow[t]{2}{*}{ Cirurgia } & Não & $14(30,4)$ \\
\hline & Sim & $32(69,6)$ \\
\hline \multirow[t]{2}{*}{ Reconstrução } & Não & $34(73,9)$ \\
\hline & Sim & $12(26,1)$ \\
\hline Tipo da & Microcirúrgico & $2(4,3)$ \\
\hline \multirow[t]{9}{*}{ reconstrução } & Supraclavicular & $1(2,2)$ \\
\hline & Peitoral maior placa e & $3(6,5)$ \\
\hline & parafuso/peitoral maior & \\
\hline & Enxerto ósseo de crista ilíaca & $1(2,2)$ \\
\hline & CHEP & $2(4,3)$ \\
\hline & Retalho supraclavicular e grácil & $1(2,2)$ \\
\hline & inervado & \\
\hline & Retalho músculo infrahióideo & $1(2,2)$ \\
\hline & Antebraço & $1(2,2)$ \\
\hline \multirow[t]{2}{*}{ EC } & Não & $19(41,3)$ \\
\hline & Sim & $27(58,7)$ \\
\hline \multirow[t]{3}{*}{ Tipo de EC } & Radical modificado & $2(4,3)$ \\
\hline & Radical & $4(8,7)$ \\
\hline & & continua \\
\hline
\end{tabular}




\begin{tabular}{|c|c|c|}
\hline \multirow[t]{2}{*}{ Variável } & \multirow{2}{*}{$\begin{array}{l}\text { Categoria / Medidas } \\
\text { Supraomohioideo }\end{array}$} & \multirow{2}{*}{$\begin{array}{c}\text { Freq. (\%) / Medidas } \\
13(28,3)\end{array}$} \\
\hline & & \\
\hline & Seletivo bilateral & $2(4,3)$ \\
\hline & Central e radical modificado & $1(2,2)$ \\
\hline & Nível 6 & $1(2,2)$ \\
\hline & IV C & $1(2,2)$ \\
\hline & Radical ampliado & $1(2,2)$ \\
\hline & Radical modificado e & $2(4,3)$ \\
\hline & supraomohioideo & \\
\hline Descrição do & Cirurgia & $16(34.8)$ \\
\hline \multirow[t]{4}{*}{ tratamento } & Cirurgia e Rt & $9(19.5)$ \\
\hline & Cirurgia+Rt+Qt & $7(15,2)$ \\
\hline & Rt-Qt & $11(23.9)$ \\
\hline & $\mathrm{Rt}$ & $3(6.5)$ \\
\hline \multirow[t]{2}{*}{ Complicações } & Não & $40(87,0)$ \\
\hline & Sim & $6(13,0)$ \\
\hline Descrição das & Osteorradionecrose mandibular & $1(2,2)$ \\
\hline \multirow[t]{4}{*}{ compicações } & Deiscência & $2(4,3)$ \\
\hline & Estenose de traquéia & $1(2,2)$ \\
\hline & Estenose de esôfago & $1(2,2)$ \\
\hline & Paralisia bilateral de prega & $1(2,2)$ \\
\hline
\end{tabular}

continua 


\begin{tabular}{|c|c|c|}
\hline Variável & Categoria / Medidas & Freq. (\%) / Medidas \\
\hline \multirow[t]{2}{*}{ Rt } & Não & $16(34,8)$ \\
\hline & Sim & $30(65,2)$ \\
\hline \multirow[t]{4}{*}{ Local } & Cervicofacial & $11(23,9)$ \\
\hline & Local & $3(6,5)$ \\
\hline & Cervicofacial e local & $10(21,7)$ \\
\hline & Cervicofacial e fossas & $6(13,0)$ \\
\hline Dose & Mín.- máx. & $1800-7020$ \\
\hline \multirow[t]{2}{*}{$(n=30)$} & Mediana & 7000 \\
\hline & Média \pm desvio padrão & $6425,0 \pm 1248,3$ \\
\hline \multirow[t]{2}{*}{ Qt } & Não & $29(63,0)$ \\
\hline & Sim & $17(37,0)$ \\
\hline Número de ciclos & Variação & $1-6$ \\
\hline de Qt & Mediana & 6 \\
\hline$(n=17)$ & Média \pm desvio padrão & $4,5 \pm 2,0$ \\
\hline Momento & Concomitante à Rt & $17(37)$ \\
\hline \multirow[t]{2}{*}{ Traqueostomia } & Não & $43(93,5)$ \\
\hline & Sim & $3(6,5)$ \\
\hline Tipo de cânula & Metálica & $3(6.5)$ \\
\hline \multirow[t]{2}{*}{ Via oral líqudo } & Não & $4(8,7)$ \\
\hline & Sim & $42(91,3)$ \\
\hline \multirow[t]{3}{*}{ Via oral nectar } & Não & $6(13,0)$ \\
\hline & Sim & $40(87,0)$ \\
\hline & & continua \\
\hline
\end{tabular}




\begin{tabular}{|c|c|c|}
\hline Variável & Categoria / Medidas & Freq. (\%) / Medidas \\
\hline \multirow[t]{2}{*}{ Via oral mel } & Não & $6(13,0)$ \\
\hline & Sim & $40(87,0)$ \\
\hline \multirow[t]{2}{*}{ Via oral pastoso } & Não & $6(13,0)$ \\
\hline & Sim & $40(87,0)$ \\
\hline \multirow[t]{2}{*}{ Via oral sólido } & Não & $13(8,3)$ \\
\hline & Sim & $33(71,7)$ \\
\hline \multirow[t]{2}{*}{ VAA } & Não & $41(89,1)$ \\
\hline & Sim & $5(10,9)$ \\
\hline \multirow[t]{2}{*}{ Tipo VAA $(n=5)$} & SNG & $3(6,5)$ \\
\hline & Gastrostomia & $2(4,3)$ \\
\hline \multirow[t]{2}{*}{ Fonoterapia } & Não & $31(67,4)$ \\
\hline & Sim & $15(32,6)$ \\
\hline
\end{tabular}

Legenda: Freq.: frequência, n: número, mín.: mínimo, máx.: máximo, dp: desvio-padrão, Rt: radioterapia, Qt: quimoterapia, RtQt: radio-quimioterapia, VAA: via alternativa de alimentação, SNG: sonda nasogástrica.

Em relação aos sintomas, um total de $24(52,2 \%)$ dos pacientes referiu inchaço, 15 (32,6\%) sensação de peso, 21 (45,6\%) rigidez no pescoço e redução do movimento, 23 (50\%) alteração na aparência, 12 (26\%) dor, 24 $(52,2 \%)$ dificuldade para falar e $30(65,2 \%)$ dificuldade para engolir.

A Tabela 2 (Apêndice) demonstra as medidas extraídas dos pontos da face e do pescoço por meio de perimetria.

A Tabela 3 demonstra a distribuição do tipo de edema (externo, interno, composto). É possível observar que houve maior ocorrência de edema composto $(73,9 \%)$. 
Tabela 2 - Distribuição da caracterização do linfedema quanto ao local: externo, interno, composto. $(n=46)$

\begin{tabular}{lcc}
\hline Variável & Categoria & Freq. (\%) \\
\hline Edema externo & Não & $41(89,1)$ \\
& Sim & $5(10,9)$ \\
Edema interno & Não & $40(87)$ \\
Edema composto & Sim & $6(13)$ \\
& Não & $12(26,1)$ \\
\hline Legenda: Freq.: frequência. & Sim & $34(73,9)$ \\
\hline
\end{tabular}

Ao analisar a distribuição da localização do edema externo, é possível verificar que houve maior ocorrência de linfedema na região de pescoço (71,7\%). Tanto no linfedema de pescoço quanto submandibular o nível de estadiamento foi maior indicando certo grau de fibrose (Tabela 4).

Tabela - 3. Distribuição do linfedema externo de acordo com a localização e estadiamento pela Escala de linfedema em CCP MDACC $(\mathrm{n}=46)$.

\begin{tabular}{llr}
\hline Variável & Categoria & Freq. (\%) \\
\hline Linfedema de face & Não & $30(65,2)$ \\
& Sim & $16(34,8)$ \\
Nível do linfedema de face & 0 & $30(65,2)$ \\
& $1 \mathrm{a}$ & $5(10,9)$ \\
Linfedema de pescoço & Não & $11(23,9)$ \\
& Sim & $13(28,3)$
\end{tabular}




\begin{tabular}{llc}
\hline Variável & Categoria & Freq. (\%) \\
\hline Nível do linfedema de & 0 & conclusão \\
pescoço & $1 \mathrm{a}$ & $13(28,3)$ \\
& $1 \mathrm{~b}$ & $3(6,5)$ \\
& 2 & $9(19,6)$ \\
Linfedema submandibular & Não & $11(23,9)$ \\
& Sim & $10(21,7)$ \\
Nivel do linfedema & 0 & $17(37)$ \\
submandibular & $1 \mathrm{a}$ & $29(63)$ \\
& $1 \mathrm{~b}$ & $17(37)$ \\
& 2 & $2(4,3)$ \\
& 3 & $7(15,2)$ \\
& & $8(17,4)$ \\
& & $126,1)$ \\
\hline
\end{tabular}

Legenda: Freq.: frequência, Niveis - 0: sem edema visível, mas o paciente relata peso; 1a: edema leve visível: sem depressão, reversível; 1b: edema com depressão leve; reversível; 2: edema com depressão firme; irreversível; sem alteração dos tecidos; 3: edema irreversível; alterações dos tecidos.

A avaliação por meio de exame baseada na Escala do Edema da Radioterapia evidenciou edema em todas as estrutras e espaços analisados. $O$ maior comprometimento foi observado em aritenoides $(73,9 \%)$, epiglote (71,7\%), espaço interaritenoideo $(69,6 \%)$ e pregas ariepiglóticas $(67,4 \%)$. Em todos os itens avaliados os resultados demonstraram um percentual maior de edema de grau moderado/severo (Tabela 5). 
Tabela 4 - Distribuição do edema interno de acordo com a Escala do edema da radioterapia $(\mathrm{n}=46)$.

\begin{tabular}{|c|c|c|}
\hline Variável & Categoria & Freq. (\%) \\
\hline Estruturas & Classificação & \\
\hline \multirow[t]{3}{*}{ Base de língua } & Normal & $25(54,3)$ \\
\hline & Discreto & $16(34,8)$ \\
\hline & Moderado/severo & $5(10,9)$ \\
\hline Parede posterior de & Normal & $20(43,5)$ \\
\hline \multirow[t]{2}{*}{ faringe } & Discreto & $8(17,4)$ \\
\hline & Moderado/severo & $18(39,1)$ \\
\hline Prega & Normal & $20(43,5)$ \\
\hline \multirow[t]{2}{*}{ faringoepiglótica } & Discreto & $5(10,9)$ \\
\hline & Moderado/severo & $21(45,6)$ \\
\hline Espaço & Normal & $14(30,4)$ \\
\hline \multirow[t]{2}{*}{ interaritenóideo } & Discreto & $4(8,7)$ \\
\hline & Moderado/severo & $28(60,9)$ \\
\hline \multirow[t]{3}{*}{ Área retrocricoidea } & Normal & $18(39,1)$ \\
\hline & Discreto & $3(6,5)$ \\
\hline & Moderado/severo & $25(54,4)$ \\
\hline \multirow[t]{3}{*}{ Aritenoides } & Normal & $12(26,1)$ \\
\hline & Discreto & $4(8,7)$ \\
\hline & Moderado/severo & $30(65,2)$ \\
\hline \multirow[t]{3}{*}{ Pregas vestibulares } & Normal & $32(69,6)$ \\
\hline & Discreto & $1(2,2)$ \\
\hline & Moderado/severo & $\begin{array}{l}13(28,3) \\
\text { continua }\end{array}$ \\
\hline
\end{tabular}




\begin{tabular}{lll}
\hline Variável & Categoria & Freq. (\%) \\
Estruturas & Classificação & \\
\hline
\end{tabular}

conclusão

\begin{tabular}{|c|c|c|}
\hline \multirow[t]{3}{*}{ Pregas vocais } & Normal & $38(82,6)$ \\
\hline & Discreto & $3(6,5)$ \\
\hline & Moderado/severo & $5(10,9)$ \\
\hline \multirow[t]{3}{*}{ Comissura anterior } & Normal & $42(91,3)$ \\
\hline & Discreto & $3(6,5)$ \\
\hline & Moderado & $1(2,2)$ \\
\hline Espaços & $\underline{\text { Classificação }}$ & \\
\hline \multirow[t]{3}{*}{ Valécula } & Normal & $22(47,8)$ \\
\hline & Discretamente reduzida & $10(21,7)$ \\
\hline & Moderadamente/severamente reduzida & $14(30,4)$ \\
\hline \multirow[t]{3}{*}{ Seios piriformes } & Normal & $23(50)$ \\
\hline & Discretamente reduzida & $5(10,9)$ \\
\hline & Moderadamente/severamente reduzida & $18(39,1)$ \\
\hline
\end{tabular}

A VED identificou resíduo em todas as estruturas de saliva e todas as consistências testadas. No caso de saliva, houve maior ocorrência em valécula $(45,6 \%)$, parede posterior de faringe (34,8\%) e penetração em 10,9\% nível 5 (em todos os pacientes) e aspiração em 8,7\% (nível 7 em 2,2\%, 8 em 6,5\%).

A avaliação com líquido foi realizada em 43 pacientes e evidenciou perda prematura em $18,6 \%$ dos casos, resíduo na valécula em 34,9\% e em seios piriformes em 25,5\%, penetração em 27,9\% (predominantemente nível 3 - 9,3\% e nível 5 - 11,6\%) e aspiração em 11,6\% (distribuídas entre os 3 níveis). 
A consistência de néctar foi oferecida para os 46 pacientes, sendo que 17,4\% apresentaram perda prematura e resíduo na valécula em 52,2\%, penetração em 34,8\% (maior frequência nível 4 - 8,7\%, nível 5 - 19,6\%) e aspiração em 6,5\%.

A avaliação com pastoso foi realizada em 39 sujeitos e demonstrou resíduo na valécula em $61,5 \%$ dos casos; $30,8 \%$ em seios piriformes; penetração em $25,6 \%$ distribuídos entre o nível 2 ao 5 e aspiração em 5\% (todas nível 8).

A deglutição com sólido foi avaliada em 37 pacientes e indicou resíduo em valécula em $43,2 \%$ dos exames, $18,9 \%$ em base de língua e penetração em 16,2\% (nível 2-2,7\%, nível 3-8,1\%, nível 4 -5,4\%).

O sintoma de rigidez e redução do movimento foi apontada em maior frequência nos sujeitos submetidos ao EC com significância estatística (23,8\% não $\times 76,2 \%$ - sim, $p=0,027)$.

A associação entre a presença de linfedema e o resíduo indicou uma diferença com maior número de casos de resíduos relacionados ao linfedema composto $(11,8 \%$ normal $X 38,2 \%$ resíduo, $p=0,012)$.

A avaliação da sensibilidade faringolaríngea foi classificada como preservada na ausência de linfedema face $(75 \%$ preservada X $25 \%$ alterada, $p=0,040)$. Em contrapartida, o exame detectou alteração nos casos de linfedema de pescoço com enfase para o nível 2 (10\% - preservada X 90\% alterada, $p=0,007)$ e para o linfedema submandibular $(41,4 \%$ - preservada $X$ $51,6 \%$ - alterada, $p=0,021)$

Houve maior ocorrência de linfedema submandibular nos pacientes tratados com Rt $(20,7 \%$ - sem Rt X $79,3 \%$ - Rt $(p=0,009)$ e alteração na 
sensibilidade faringolaríngea, demonstrando que o grupo que fez Rt tinha a sensibilidade alterada (19\% - preservada X $81 \%$ - alterada, $p=0,040$ ).

Na VED foi identificado resíduo em maior ocorrência quando se comparou os sujeitos de acordo com o tratamento, apontando para os pacientes do grupo com Rt $(22,2 \%$ - sem Rt $X 77,8 \%-R t, p=0,001)$. A análise de acordo com a Escala de Penetração e Aspiração apontou para a penetração na consistência pastosa para os sujeitos submetidos ao tratamento combinado de Rt $(0-$ sem Rt X 100\% - Rt, $p=0,007)$.

A comparação entre padrão de sensibilidade faringolaríngea de acordo com a Escala de Penetração e Aspiração indicou maior ocorrência de alteração nos casos de penetração para todas as consistências e para penetração e aspiração de saliva. As diferenças apontaram significância estatística (Tabela $6)$.

Tabela 5 - Associação entre a Escala de Penetração e Aspiração (saliva, líquido, néctar, pastoso e sólido) de acordo com a sensibilidade faringolaríngea.

\begin{tabular}{|c|c|c|c|c|}
\hline \multirow[t]{3}{*}{ Variável } & \multirow[t]{3}{*}{ Categoria } & \multicolumn{2}{|c|}{ Sensibilidade } & \multirow[t]{3}{*}{ Valor de $p$} \\
\hline & & Preservada & Alterada & \\
\hline & & \multicolumn{2}{|c|}{ Freq. (\%) } & \\
\hline Penetração & Não & $25(61)$ & $16(39)$ & 0,015 \\
\hline Saliva & Sim & $0(0)$ & $5(100)$ & \\
\hline Aspiração & Não & $25(59,5)$ & $17(40,5)$ & 0,037 \\
\hline Saliva & Sim & $0(0)$ & $4(100)$ & \\
\hline
\end{tabular}




\begin{tabular}{|c|c|c|c|c|}
\hline \multirow[t]{3}{*}{ Variável } & \multirow[t]{3}{*}{ Categoria } & \multicolumn{2}{|c|}{ Sensibilidade } & \multirow[t]{3}{*}{ Valor de $p$} \\
\hline & & Preservada & Alterada & \\
\hline & & \multicolumn{2}{|c|}{ Freq. (\%) } & \\
\hline & & & & conclusão \\
\hline Penetração & Não & $21(67,7)$ & $10(32,3)$ & $0,040^{\star}$ \\
\hline líquido & Sim & $4(33,3)$ & $8(66,7)$ & \\
\hline Aspiração & Não & $24(63,2)$ & $14(36,8)$ & 0,144 \\
\hline Líquido & Sim & $1(20)$ & $4(80)$ & \\
\hline Penetração & Não & $21(70)$ & $9(30)$ & $0,004^{\star}$ \\
\hline néctar & Sim & $4(25)$ & $12(75)$ & \\
\hline Aspiração & Não & $25(58,1)$ & $18(41,9)$ & 0,088 \\
\hline Néctar & Sim & $0(0)$ & $3(100)$ & \\
\hline Penetração & Não & $21(72,4)$ & $8(27,6)$ & 0,007 \\
\hline pastoso & Sim & $2(20)$ & $8(80)$ & \\
\hline Aspiração & Não & $23(62,2)$ & $14(37,8)$ & NA \\
\hline pastoso & Sim & $0(0)$ & $2(100)$ & \\
\hline Penetração & Não & $21(67,7)$ & $10(32,3)$ & 0,031 \\
\hline sólido & Sim & $1(16,7)$ & $5(83,3)$ & \\
\hline Aspiração & Não & $22(59,5)$ & $15(40,5)$ & NA \\
\hline Sólido & Sim & $0(0)$ & $0(0)$ & \\
\hline
\end{tabular}

Legenda: Freq.: frequência, $p$-valor obtido pelo teste exato de Fisher, * $p$-valor obtido pelo teste de frequências do quiquadrado, NA = não avaliável estatisticamente

Outro aspecto importante relacionado à deglutição é que todos os sujeitos que apresentaram resíduo com a consistência pastosa evoluíram com penetração ( 0 ausência de resíduo X 100\% presença de resíduo, $p=0,040$ ) 
A associação entre o edema interno e o tratamento combinado de Rt apontou maior percentual de edema para o grupo submetido à RT em quase todas as estruturas e espaços. O EC também não indicou a associação com o edema interno (Tabela 6).

A correlação entre o edema interno e o resíduo de qualquer consistência e a sensibilidade faringolaríngea demonstrou maior número de casos para os sujeitos com edema interno em várias estruturas e espaços analisados com significância estatística (Tabela 7). 
Table 6 - Associação entre o edema interno, Rt e EC ( $n=46)$.

\begin{tabular}{|c|c|c|c|c|c|c|c|}
\hline \multirow{2}{*}{$\begin{array}{l}\text { Variável } \\
\text { Estrutura }\end{array}$} & \multirow{3}{*}{$\begin{array}{l}\text { Categoria } \\
\text { Edema }\end{array}$} & \multicolumn{2}{|c|}{ RT } & \multicolumn{4}{|c|}{ EC } \\
\hline & & Não & Sim & $p$-valor & Não & Sim & $p$-valor \\
\hline & & \multicolumn{2}{|c|}{ Freq. (\%) } & \multicolumn{4}{|c|}{ Freq. (\%) } \\
\hline Base de & Não & $13(52)$ & $12(48)$ & 0,007 & $8(32)$ & $17(68)$ & 0,162 \\
\hline língua & Sim & $3(14,3)$ & $18(85,7)$ & & $11(52,4)$ & $10(47,6)$ & \\
\hline Parede posterior & Não & $13(65)$ & $7(35)$ & $<0,001$ & $6(30)$ & $14(70)$ & 0,172 \\
\hline de faringe & Sim & $3(11,5)$ & $23(88,5)$ & & $13(50)$ & $13(50)$ & \\
\hline \multirow[t]{2}{*}{ Epiglote } & Não & $9(69,2)$ & $4(30,8)$ & 0,002 & $3(23,1)$ & $10(76,9)$ & 0,115 \\
\hline & Sim & $7(21,2)$ & $26(78,8)$ & & $16(48,5)$ & $17(51,5)$ & \\
\hline Prega & Não & $12(60)$ & $8(40)$ & 0,002 & $4(20)$ & $16(80)$ & 0,010 \\
\hline faringoepiglótica & Sim & $4(15,4)$ & $22(84,6)$ & & $15(57,7)$ & $11(42,3)$ & \\
\hline Prega & Não & $10(66,7)$ & $5(33,3)$ & 0,002 & $4(26,7)$ & $11(73,3)$ & 0,161 \\
\hline ariepiglótica & Sim & $6(19,4)$ & $25(80,6)$ & & $15(48,4)$ & $16(51,6)$ & \\
\hline
\end{tabular}




\begin{tabular}{|c|c|c|c|c|c|c|c|}
\hline \multirow{2}{*}{$\begin{array}{l}\text { Variável } \\
\text { Estrutura }\end{array}$} & \multirow{2}{*}{$\begin{array}{l}\text { Categoria } \\
\text { Edema }\end{array}$} & \multicolumn{2}{|c|}{ RT } & \multicolumn{4}{|c|}{$\mathrm{EC}$} \\
\hline & & Não & Sim & $p$-valor & Não & Sim & $p$-valor \\
\hline & & \multicolumn{2}{|c|}{ Freq. (\%) } & \multicolumn{4}{|c|}{ Freq. (\%) } \\
\hline & & & & & & & continuação \\
\hline Espaço & Não & $7(50)$ & $7(50)$ & 0,152 & $3(21,4)$ & $11(78,6)$ & 0,070 \\
\hline interaritenoideo & Sim & $9(28,1)$ & $23(71,9)$ & & $16(50)$ & $16(50)$ & \\
\hline Área & Não & $9(50)$ & $9(50)$ & 0,082 & $4(22,2)$ & $14(77,8)$ & 0,035 \\
\hline Retrocricoidea & Sim & $7(25)$ & $21(75)$ & & $15(53,6)$ & $13(46,4)$ & \\
\hline Aritenoides & Não & $7(58,3)$ & $5(41,7)$ & 0,046 & $3(25)$ & $9(75)$ & 0,182 \\
\hline & Sim & $9(26,5)$ & $25(73,5)$ & & $16(47,1)$ & $18(52,9)$ & \\
\hline Pregas & Não & $14(36,8)$ & $14(36,8)$ & 0,694 * & $14(36,8)$ & $24(63,2)$ & 0,246 \\
\hline Vocais & Sim & $2(25)$ & $2(25)$ & & $5(62,5)$ & $3(37,5)$ & \\
\hline Comissura & Não & $16(38,1)$ & $26(61,9)$ & $0,282^{*}$ & $16(38,1)$ & $26(61,9)$ & 0,292 \\
\hline Anterior & Sim & $0(0)$ & $4(100)$ & & $3(75,0)$ & $1(25)$ & continua \\
\hline
\end{tabular}




\begin{tabular}{|c|c|c|c|c|c|c|c|}
\hline Variável & Categoria & \multicolumn{2}{|c|}{ RT } & \multicolumn{4}{|c|}{ EC } \\
\hline Estrutura & Edema & Não & Sim & $p$-valor & Não & Sim & $p$-valor \\
\hline & & \multicolumn{3}{|c|}{ Freq. (\%) } & \multicolumn{3}{|c|}{ Freq. (\%) } \\
\hline
\end{tabular}

\section{Espaços}

$\begin{array}{llcccccc}\text { Valécula } & \text { Normal } & 13(59.1) & 9(40.9) & 0,001 & 7(31.8) & 15(68.2) & 0,211 \\ & \text { Reduzido } & 3(12,5) & 21(87,5) & & 12(50) & 12(50) & \\ \text { Seios } & \text { Normal } & 14(60,9) & 9(39,1) & <0,001 & 6(26,1) & 17(73,9) & 0,036 \\ \text { Piriformes } & \text { Reduzido } & 2(8,7) & 21(91,3) & & 13(56,5) & 10(43,5) & \end{array}$

Legenda: Freq.: frequência, Rt: tratamento combinado com RT, Ec: esvaziamento cervical, p-valor obtido pelo teste de frequências do qui-quadrado, * pvalor obtido pelo teste exato de Fisher 
Tabela 7 - Associação entre o edema interno, o resíduo e a sensibilidade faringolaríngea ( $\mathrm{n}=46)$.

\begin{tabular}{|c|c|c|c|c|c|c|c|}
\hline \multirow{2}{*}{$\begin{array}{l}\text { Variável } \\
\text { Estrutura }\end{array}$} & \multirow{3}{*}{$\begin{array}{l}\text { Categoria } \\
\text { Edema }\end{array}$} & \multicolumn{2}{|c|}{ Resíduo } & \multicolumn{4}{|c|}{ Sensibilidade Faringol. } \\
\hline & & Não & Sim & $p$ valor & Preservada & Alterada & $p$ valor \\
\hline & & \multicolumn{2}{|c|}{ Freq. (\%) } & \multicolumn{4}{|c|}{ Freq. (\%) } \\
\hline Base de & Não & $8(32)$ & $17(68)$ & 0,066 & $15(60)$ & $10(40)$ & 0,401 \\
\hline Língua & Sim & $2(9,5)$ & $19(90,5)$ & & $10(47,6)$ & $11(52,4)$ & \\
\hline Parede posterior & Não & $7(35)$ & $13(65)$ & 0,077 & $13(65)$ & $7(35)$ & 0,203 \\
\hline de faringe & Sim & $3(11,5)$ & $23(88,5)$ & & $12(46,2)$ & $14(53,8)$ & \\
\hline \multirow[t]{2}{*}{ Epiglote } & Não & $7(53,8)$ & $6(46,2)$ & $0,020^{*}$ & $8(61,5)$ & $5(38,5)$ & 0,539 \\
\hline & Sim & $29(8,9)$ & $4(12)$ & & $17(51,5)$ & $16(48,5)$ & \\
\hline Prega & Não & $7(35)$ & $13(65)$ & 0,077 & $13(65,0)$ & $7(35)$ & 0,203 \\
\hline faringoepiglótica & Sim & $3(11,5)$ & $23(88,5)$ & & $12(46,2)$ & $14(53,8)$ & \\
\hline Prega & Não & $8(53,3)$ & $7(46,7)$ & $0,001^{*}$ & $10(66,7)$ & $5(33,3)$ & 0,243 \\
\hline ariepiglótica & Sim & $2(6,5)$ & $29(93,5)$ & & $15(48,4)$ & $16(51,6)$ & \\
\hline
\end{tabular}




\begin{tabular}{|c|c|c|c|c|c|c|c|}
\hline \multirow{2}{*}{$\begin{array}{l}\text { Variável } \\
\text { Estrutura }\end{array}$} & \multirow{3}{*}{$\begin{array}{l}\text { Categoria } \\
\text { Edema }\end{array}$} & \multicolumn{2}{|c|}{ Resíduo } & \multicolumn{4}{|c|}{ Sensibilidade Faringol. } \\
\hline & & Não & Sim & $p$ valor & Preservada & Alterada & $p$ valor \\
\hline & & \multicolumn{2}{|c|}{ Freq. (\%) } & \multicolumn{4}{|c|}{ Freq. (\%) } \\
\hline & & & & & & & continuação \\
\hline Espaço & Não & $6(42,9)$ & $8(57,1)$ & 0,047 & $7(50)$ & $7(50)$ & 0,695 \\
\hline interaritenoideo & Sim & $4(12,5)$ & $28(87,5)$ & & $18(56,2)$ & $14(43,8)$ & \\
\hline Área & Não & $7(38,9)$ & $11(61,1)$ & $0,033^{*}$ & $11(61,1)$ & $7(38,9)$ & 0,460 \\
\hline retrocricoidea & Sim & $3(10,7)$ & $25(89,3)$ & & $14(50)$ & $14(50)$ & \\
\hline \multirow[t]{2}{*}{ Aritenoides } & Não & $5(41,7)$ & $7(58,3)$ & 0,098 & $7(58,3)$ & $5(41,7)$ & 0,747 \\
\hline & $\operatorname{Sim}$ & $5(14,7)$ & $29(85,3)$ & & $18(52,9)$ & $16(47,1)$ & \\
\hline Pregas & Não & $10(31,2)$ & $22(68,8)$ & $0,020^{*}$ & $17(53,1)$ & $15(46,9)$ & 0,801 \\
\hline vestibulares & Sim & $0(0)$ & $14(100)$ & & $8(57,1)$ & $6(42,9)$ & \\
\hline Pregas & Não & $8(21)$ & $30(79)$ & 0,999 & $22(57,9)$ & $16(42,1)$ & 0,439 \\
\hline Vocais & $\operatorname{Sim}$ & $2(25)$ & $6(75)$ & & $3(37,5)$ & $5(62,5)$ & \\
\hline
\end{tabular}




\begin{tabular}{|c|c|c|c|c|c|c|c|}
\hline \multirow{2}{*}{$\begin{array}{l}\text { Variável } \\
\text { Estrutura }\end{array}$} & \multirow{2}{*}{$\begin{array}{l}\text { Categoria } \\
\text { Edema }\end{array}$} & \multicolumn{2}{|c|}{ Resíduo } & \multicolumn{4}{|c|}{ Sensibilidade Faringol. } \\
\hline & & Não & Sim & $p$ valor & Preservada & Alterada & $p$ valor \\
\hline & & \multicolumn{2}{|c|}{ Freq. (\%) } & \multicolumn{4}{|c|}{ Freq. (\%) } \\
\hline & & & & & & & conclusão \\
\hline Comissura & Não & $10(23,8)$ & $32(76,2)$ & 0,562 & $23(54,8)$ & $19(45,2)$ & $0,999^{*}$ \\
\hline Anterior & Sim & $0(0)$ & $4(100)$ & & $2(50)$ & $2(50)$ & \\
\hline \multicolumn{8}{|l|}{ Espaços } \\
\hline \multirow[t]{2}{*}{ Valécula } & Normal & $8(36,4)$ & $14(63,6)$ & $0,021^{*}$ & $13(59,1)$ & $9(40,9)$ & 0,536 \\
\hline & Reduzido & $2(8,3)$ & $22(91,7)$ & & $12(50)$ & $12(50)$ & \\
\hline Seios & Normal & $8(34,8)$ & $15(65,2)$ & 0,032 & $16(69,6)$ & $7(30,4)$ & 0,038 \\
\hline Piriformes & Reduzido & $2(8,7)$ & $21(91,3)$ & & $9(39,1)$ & $14(68,9)$ & \\
\hline
\end{tabular}

Legenda: Freq.: frequência, faringol.: farongolaríngea p-valor obtido pelo teste de frequências do qui-quadrado, * $\mathrm{p}$-valor obtido pelo teste exato de Fisher 



\section{DISCUSSÃO}

Nas últimas décadas, o CCP sido tratado por meio de operações, em muitos casos, extensas, que levam o paciente a sentir dor crônica, causando desfiguração e alterações funcionais. Com as técnicas de Rt e os agentes quimioterápicos, os tratamentos utilizados combinaram esses recursos com objetivo de poupar os órgãos, preservar o tecido sem comprometer a sobrevivência e o controle da doença, mas, em realidade, nem sempre preservam a função ${ }^{90,91}$. Na casuística estudada, observaram-se poucos casos de complicações, sendo três relacionados ao efeito da RtQt (estenose de traqueia, esôfago e osteoradionecrose), uma associada à extensão do tumor e comprometimento do ramo do nervo vago levando à paralisia bilateral de prega vocal e outros dois casos de deiscência. Todos esses pacientes tiveram parte da função deglutitória comprometida pelas sequelas e dois destes também com importante alteração na aparência.

Alguns sintomas foram apontados na anamnese, sendo a dificuldade para engolir $(65,2 \%)$ e falar $(52,2 \%)$, inchaço $(52,2 \%)$, alteração na aparência (50\%), rigidez no pescoço e redução do movimento do pescoço (45.6\%) os que foram referidos com maior frequência. Alguns trabalhos relacionam a ocorrência do linfedema secundário em CCP às terapias mutimodais com sintomas diversos como rigidez no pescoço, dificuldade de deglutição, voz, fala, respiração, perda de peso e desfiguramento com consequente prejuízo do ponto de vista psicossocial. O linfedema após o HNC geralmente está relacionado às regiões 
acometidas pelo tumor e adjacentes a ele e seu reflexo é determinado de acordo com a severidade e o tratamento empregado $9,15,17,19$.

Quando avaliamos a relação entre os sintomas e as variáveis analisadas, observamos associação entre a redução do movimento do pescoço e o tratamento de EC. É provável que a ausência de relação entre o sintoma de dificuldade de deglutição e o linfedema neste estudo deva-se ao fato de que, em muitos casos, a disfagia foi subvalorizada e/ou não reconhecida pelos participantes, já que os estudos apontam para importante associação entre a severidade do linfedema e os sintomas de deglutição 9,15,17,19,74.

O linfedema foi diagnosticado em $97,8 \%$ dos pacientes, sendo a maior parte $(73,9 \%)$ do tipo composto (interno e externo), seguido do linfedema externo de pescoço $(71,7 \%)$ e submandibular $(63 \%)$ com predomínio de níveis mais severos indicando certo grau de fibrose.

Apenas o linfedema de face $(34,8 \%)$ foi classiifcado de nível 1a e 1b, indicando padrão de reversibilidade nos tecidos. A sensibilidade faringolaríngea foi significativamente maior nos sujeitos que não apresentaram o linfedema de face $(p=0.040)$. Isto demonstra que o tecido que não é acometido pelo linfedema pode ter melhor desempenho funcional pela preservação das condições sensoriais e motoras na ausência do inchaço ${ }^{16,17}$.

O tratamento combinado com Rt implicou alterações importantes, como a associação com a ocorrência de linfedema submandibular em $79,3 \%$ dos avaliados. Um estudo conduzido com o fim de documentar se as alterações na anatomia e função linfática ocorrem durante o curso e a recuperação do tratamento para o CCP observou que a drenagem linfática externa nestes pacientes é transitoriamente remodelada em resposta ao câncer, à cirurgia e 
Rt. Em pacientes com doença unilateral, os padrões de drenagem linfática assimétrica foram observados antes do tratamento. A Rt associada à cirurgia extensa e/ou EC resultou no aparecimento de refluxo dérmico linfático, começando de dias a várias semanas após o início da Rt fracionada, enquanto regiões contralaterais submetidas à mesma ou Rt atenuada, mas sem dissecção de linfonodos, não desenvolveu padrões dérmicos de refluxo. Embora essas alterações linfáticas possam ser indicativas de respostas imunes anti-tumorais induzidas por radiação, que não foram resolvidas devido à ruptura cirúrgica das vias de drenagem, seu prolongamento pode estar associado ao desenvolvimento futuro de fibrose e linfedema ${ }^{92}$.

A Escala do Edema da Radioterapia apontou para edema interno em quase todas as estruturas e espaços avaliados com predomínio do grau moderado/severo e alteração de sensibilidade faringolaríngea em $45,6 \%$ dos exames. O percentual de pacientes com essas alterações foi maior nos indivíduos do grupo Rt ( $81 \%$ - alteração de sensibilidade faringolaríngea e edema em quase todas as estruturas do grupo Rt). Sabe-se que tanto a cirurgia quanto a radiação ionizante constituem um importante componente de tratamento multimodal do CCP. A excisão cirúrgica e a reconstrução são consideradas eventos que podem levar à fibrose ao redor da incisão, na anastomose ou área de déficit tecidual. Essa fibrose induzida cirurgicamente é parte do processo normal de cicatrização da ferida ${ }^{93-96}$. Quando a Rt é combinada ao EC, a ruptura dos vasos linfáticos pode resultar em estase linfática e refluxo dérmico ou no preenchimento dos capilares linfáticos dérmicos. Se não for resolvida, essa ruptura leva à inflamação crônica, edema, 
fibrose, deposição de tecido adiposo e, finalmente, a déficits funcionais e desfiguração ${ }^{15,74,97-100}$.

A VED identificou resíduo tanto de saliva como para as consistências oferecidas na avaliação, bem como penetração e aspiração, exceto para sólido. O percentual de resíduos foi maior para a consistência pastosa e para os pacientes portadores de linfedema composto. Estima-se que a coexistência do linfedema interno e externo interfere na integridade dos tecidos e músculos externos e internos levando à fibrose, redução da força e da amplitude do movimento, com consequência no desempenho do fluxo do bolo alimentar. As consistências mais espessas em particular são mais difíceis de evoluir ao longo da faringe e podem resultar em estase. Quanto mais severo o edema, maior a dificuldade. Muitos destes pacientes são submetidos a tratamento combinado de Rt com alterações associadas, como a xerostomia. Neste estudo, não investigamos a ocorrência de xerostomia, no entanto, muitos pacientes relataram esta queixa. É provável que estes fatores associados sejam responsáveis pelo maior percentual de penetração com a consistência pastosa. A literatura afirma que o inchaço severo em qualquer estrutura da Escala de Patterson provoca disfunção de deglutição e que pacientes com linfedema ou fibrose faríngea, por exemplo, são mais propensos a desenvolver disfagia ${ }^{16,86}$.

O exame objetivo auxiliou a constatar essas afirmações pela associação entre o edema interno e o resíduo em quase todas as estrututras faringolaríngeas. Outro dado importante é a alteração de sensibilidade faringolaríngea em seios piriformes na vigência do edema interno. Estes dois fatores (resíduo e alteração sensorial) oferecem riscos pontenciais à aspiração 
silente e, no caso destes pacientes, pode justificar a ocorrências de penetração e aspiração.

A patofisiologia da fibrose induzida pela Rt ainda não foi definitivamente esclarecida e a lesão microvascular parece ser um importante componente do dano ao sistema nervoso e outros tecidos, progredindo indefinidamente. Esse processo pode ser caracterizado em três fases: 1- Fase pré-fibrótica, que é usualmente assintomática e caracterizada pela disfunção das células endoteliais. A lesão por radiação é evidenciada por sinais de inflamação local crônica, não específica, aumento da permeabilidade vascular e edema. A disfunção celular endotelial e a trombose vascular podem resultar em necrose microsvascular e subsequente isquemia local; 2- Fase de organização constitutiva, que é o estágio em que ose sintomas são desenvolvidos. O tecido irradiado contém áreas irregulares de fibroblastos (miofibroblastos) na matriz extracelular desorganizada que é encontrada adjacente aos fibroblastos senescentes (fibrócitos) em uma matriz densamente esclerótica. $\mathrm{O}$ dano aos tecidos das células dos tecidos conectivos e endoteliais junto com a ação das citocinas mantém e perpetua a fibrose; e 3- Fase fibroatrófica tardia, em que o tecido irradiado torna-se progressivamente denso como resultado de uma remodulação sucessiva da matriz extracelular. Os poucos fibroblastos que sobrevivem são encapsulados por uma densa matriz extracelular. Este estágio pode progredir por anos ou décadas após a Rt. O resultado é um tecido que é pouco vascularizado, friável e frágil. O conhecimento e a compreensão deste mecanismo podem auxiliar na identificação precoce desse fenômeno e promover a possibilidade de tratamento precoce no intuito de minimizar suas sequelas. Mais estudos sobre os mecanismos que regem os padrões anormais 
de fluxo linfático que ocorrem antes, durante e após o tratamento do CCP são necessários para melhorar a qualidade da sobrevida ${ }^{101-102}$.

Não foi possível analisar a associação entre o linfedema e/ou a presença de resíduo e o sítio da doença pelo número da amostra e a distribuição dos diversos vários sítios encontrados nela. Para tal, seria necessário um número maior de avaliações.

Em nosso estudo, a avaliação da deglutição foi realizada por meio de videoendoscopia. A ferramenta proporcionou uma visão mais clara das estruturas faríngeas e possibilitou avaliar tanto a deglutição de saliva e alimentos quanto classificar o grau de resíduo faríngeo e de penetração e aspiração. Apesar de a aspiração ser o foco primário da avaliação objetiva pelo risco de broncopneumonia e morbidade que ela oferece, sabe-se que o resíduo também pode levar à penetração e aspiração. Entretanto, muitos dos pacientes submetidos ao tratamento para o CCP têm dificuldades de deglutição, mas não aspiram. Meyer et al. consideram que a disfagia nesses casos é caracterizada por alteração na propulsão, no trânsito faríngeo e no clareamento do bolo que levam ao resíduo com impacto importante na qualidade de vida. $\mathrm{O}$ aumento do resíduo faríngeo, particularmente, tem um efeito mais evidente no estado funcional, independentemente do escore de penetração e aspiração. Isto parece indicar que o resíduo em diferentes locais do trato aerodigestório superior reflete em diferentes déficits no mecanismo da deglutição. Assim, o resíduo poderia ser considerado uma medida primária da função da deglutição e ser um alvo para identificação, avaliação e dos resultados do tratamento da deglutição ${ }^{103}$. 
As alterações detectadas à VED corroboram as afirmações supracitadas. O resíduo e a penetração são eventos sistemáticos após o tratamento para o CCP, sendo mais evidente para o pastoso. No protocolo de avaliação utilizado neste grupo de pacientes, foram oferecidos apenas $5 \mathrm{~mL}$ e $10 \mathrm{~mL}$ para cada consistência, com resultados indicando alterações nas duas escalas empregadas para a análise. É plausível supor que, em quantidades maiores, a frequência provavelmente será maior, fato que geralmente ocorre na vida diária do sujeito que se alimenta por via oral exclusiva. Este aspecto é um indicador importante para o direcionamento de critérios de avaliação e acompanhamento desde o período mais precoce de tratamento. A detecção, avaliação e caracterização do linfedema cervicofacial e faringolaríngeo devem fazer parte da prática diária do fonoaudiólogo e sua constatação pode ser um indicador da coexistência de alterações na biomecânica da deglutição, principalmente nos casos de linfedema composto e/ou com tratamento combinado de Rt.

O exame de VED demonstrou ser uma ferramenta importante no rastreamento do resíduo e da penetração em diferentes texturas.

Mesmo com uma amostra pequena, o estudo permitiu a constatação de que o linfedema é um fenômeno comum no HNC com impacto importante no desempenho da deglutição. 




\section{CONCLUSÕES}

O linfedema cervicofacial e faringolaríngeo são eventos comuns após o tratamento para o CCP de grau mais avançado indicando tendência à fibrose.

A deglutição é caracterizada pela presença de resíduo, alteração da sensibilidade faringolaríngea, penetração e aspiração.

O tratamento combinado de Rt está diretamento associado com 0 linfedema e o pior desempenho na deglutição. 




\title{
8. ANEXOS
}

\author{
ANEXO A - Aprovação pelo Comitê de Ética em Pesquisa da \\ Faculdade de Medicina da Universidade de São Paulo sob o \\ número 075/14, em 12 de maio de 2014.
}

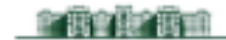 \\ MEDICINA \\ TSP \\ COMITÊ DE ÉTICA EM PESQUISA
}

\begin{abstract}
APROVAÇÃO
o Comitê de Ética em Pesquisa da Faculdade de Medicina da Universidade de São Paulo, em sessão de 21/05/2014, APROVOU o Protocolo de Pesquisa no 137/14 intitulado: "AVALLAÇÃo DA RFLAÇão ENTRE O LINFEDEMA CÉRVICO-FACLAL E A LARNGE APÓS ESVAZLAMENTO CERVICAL" apresentado pelo Departamento de CIRURGLA

Cabe ao pesquisador elaborar e apresentar ao CEPFMUSP, os relatórios parciais e final sobre a pesquisa (Resolução do Conselho Nacional de Saúde $n^{\circ} 466 / 12$ ).
\end{abstract}

Pesquisador (a) Responsável: Rogério Aparecido Dedivitis

Pesquisador (a) Executante: Débora dos Santos Queija

CEP-FMUSP, 26 de Maio de 2014.

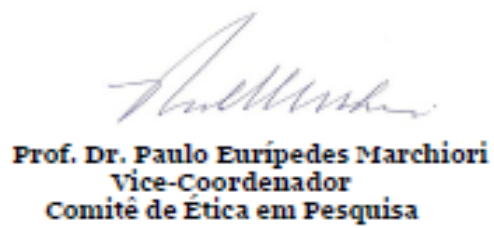

Comitê de Ética em Pesquisa 
ANEXO B - Termo de consentimento livre e esclarecido.

\section{HOSPITAL DAS CLÍNICAS DA FACULDADE DE MEDICINA DA UNIVERSIDADE DE SÃO PAULO-HCFMUSP}

TERMO DE CONSENTIMENTO LIVRE E ESCLARECIDO PARA OS PACIENTES DADOS DE IDENTIFICAÇÃO DO PARTICIPANTE DA PESQUISA OU RESPONSÁVEL LEGAL

1. NOME:

DOCUMENTO DE IDENTIDADE № : .GENERO: .M $\square \mathrm{F} \square$

DATA NASCIMENTO: .....................

ENDEREÇO №

APTO: BAIRRO:

CIDADE CEP:

TELEFONE: DDD

2. RESPONSÁVEL LEGAL

NATUREZA (grau de parentesco, tutor, curador etc.)

DOCUMENTO DE IDENTIDADE :

SEXO: $M \square F \square$

DATA NASCIMENTO.: .....................

ENDEREÇO: №.

APTO: BAIRRO

CIDADE:

CEP:

TELEFONE: DDD ( )

\section{DADOS SOBRE A PESQUISA}

1. TÍTULO DO PROTOCOLO DE PESQUISA - Avaliação da relação entre o linfedema cérvicofacial e a laringe após esvaziamento cervical

2. PESQUISADOR : Prof. Dr. Rogério Aparecido DEdivitis

CARGO/FUNÇÃO: Médico INSCRIÇÃO CONSELHO REGIONAL CRM: 65803

UNIDADE DO HCFMUSP: Departamento de Cirurgia de Cabeça e Pescoço

3. AVALIAÇÃO DO RISCO DA PESQUISA:

$$
\begin{aligned}
& \text { RISCO MÍNIMO (X) } \\
& \text { RISCO BAIXO } \square
\end{aligned}
$$

$$
\begin{aligned}
& \text { RISCO MÉDIO } \square \\
& \text { RISCO MAIOR } \square
\end{aligned}
$$

4. DURAÇÃO DA PESQUISA : 2 anos

Essas informações estão sendo fornecidas para sua participação voluntária neste estudo, que tem como objetivo avaliar a presença, estadiamento e características do linfedema facial, cervical e laríngeo, bem como a relação destes entre si, após o tratamento cirúrgico para o câncer de cabeça e pescoço, seguido ou não de tratamento adjuvante.

As avaliações serão realizadas por duas fonoaudiólogas e uma fisioterapeuta e um médico cirurgião de cabeça e pescoço no ambulatório de Fonoaudiologia e de Cirurgia de Cabeça e Pescoço.

Para a análise da face e do pescoço será usada uma caneta antialérgica para fazer as marcações das medidas que serão computadas com uma fita antropométrica e as imagens fotografadas de frente e perfil.

$E$, para a análise da laringe será realizado exame laringológico no Ambulatório de Cirurgia de Cabeça e Pescoço do HCFMUSP por médico cirurgião, junto com a fonoaudióloga pesquisadora.

O exame é feito com um tubo fino e flexível inserido nem uma das narinas. Pode ser desconfortável, mas não deve causar dor. Se isso ocorrer, poderá pedir para o médico retirar a 
fibra (tubo flexível). O médico tentará novamente por outra narina, mas se houver desconforto excessivo, poderá solicitar para que o exame seja interrompido.

Assim que sentir que os testes possam ser realizados, o médico solicitará que respire normalmente, puxe o ar com força e realize alguns sons, além disso, serão ofertadas (se possível) uma pequena quantidade de líquido (5 e $20 \mathrm{~mL}$ ), líquido engrossado na consistência de néctar (5 e $20 \mathrm{~mL})$ e pastoso $(10 \mathrm{~mL})$, um pedaço pequeno de pão.

O (a) Sr. (a) não terá benefício financeiro com sua participação nesta pesquisa, pois trata-se de estudo com objetivo de melhorar os procedimentos terapêuticos na área de voz, bem como os instrumentos de avaliação. Somente no final do estudo poderemos concluir a presença de algum benefício que poderá ser aplicado na avaliação fonoaudiológica e tratamento de outros pacientes. É importante ressaltar que não há procedimentos alternativos que possam ser vantajosos pelos quais o (a) Sr. (a) possa optar.

Em qualquer etapa do estudo o (a) Sr. (a) terá acesso aos profissionais responsáveis pela pesquisa para esclarecimento de eventuais dúvidas. O principal investigador é a Dr. Rogério Aparecido Dedivitis, que pode ser encontrado no Ambulatório de Cirurgia de Cabeça e Pescoço, no Prédio dos Ambulatórios, 6aar, bloco 7A. Se houver a necessidade de alguma consideração ou dúvida sobre a ética da pesquisa, entre em contato com o Comitê de Ética em Pesquisa (CEP) - Rua Ovídio Pires de Campos, 225 - 5o andar - tel: 3069-6442 ramais 16, 17, 18 ou 20, FAX: 3069-6442 ramal 26 - e-mail: cappesq@hcnet.usp.br. É garantida a liberdade da retirada do seu consentimento a qualquer momento, assim como a desistência em relação à participação no estudo, sem qualquer prejuízo à continuidade de seu tratamento na Instituição.

É garantido a todos os participantes o direito de confidencialidade, uma vez que as informações obtidas serão analisadas em conjunto com as de outros pacientes e não serão divulgados dados de identificação. É garantido também o seu direito em relação ao conhecimento dos resultados da pesquisa. Não há despesas pessoais em qualquer fase do estudo, incluindo exames e consultas. Fica aqui explicitado o compromisso do pesquisador de utilizar os dados e o material coletado somente para esta pesquisa.

Acredito ter sido suficientemente informado por meio do que li, ou do que foi lido para mim, sobre o estudo Avaliação da relação entre o linfedema cérvico-facial e a laringe após esvaziamento cervical. Eu discuti com as pesquisadoras sobre a minha decisão voluntária em participar da pesquisa e ficaram claros para mim quais são os propósitos do estudo, os procedimentos a serem realizados, seus desconfortos e riscos, as garantias de confidencialidade e de esclarecimentos permanentes. Ficou claro também que minha participação é isenta de despesas. Concordo voluntariamente em participar deste estudo e poderei retirar o meu consentimento a qualquer momento, antes ou durante o mesmo, sem penalidades ou prejuízo ou perda de qualquer benefício que eu possa ter adquirido ou em relação ao meu atendimento neste serviço.

Assinatura do participante/representante legal

Assinatura da testemunha

Data $\frac{1}{1}$

(nos casos de pacientes menores de 18 anos, analfabetos, semi-analfabetos ou portadores de deficiência auditiva ou visual)

PARA O RESPONSÁVEL PELO PROJETO:

Declaro que obtive de forma apropriada e voluntária o Consentimento Livre e Esclarecido deste participante ou de seu representante legal para a participação neste estudo.

Assinatura do responsável pelo estudo

Data

11 
ANEXO C - Protocolo de avaliação

I - IDENTIFICAÇÃO RGH:

Nome:

Data de Nascimento: ___ 1__ I I I I _ I _ I

Endereço:

Bairro: Cidade:

Telefone (1): Telefone(2):

Raça: (1) branca; (2) amarela; (3) negra Gênero: (1) F; (2) M

Tabagismo: (0) não; (1) sim Etilismo: (0) não; (1) sim

\section{II- DADOS DO TUMOR}

Sítio da doença: (1) Boca; (2) Orofaringe; (3) Rinofaringe; (4) Laringe;

(5) Primário oculto; (6) Infraglote; (7) Tireóide; (8) Face

Estadiamento: T: 1 (1); 2 (2); 3 (3); 4 (4); x (5); 1b (6); não avaliável (7)

$\mathrm{N}$ : (0) N0; (1) N1; (2) N2; (3) N2a; (4) N2b; (5) N2c; (6) N3

$\mathrm{M}:(0) \mathrm{M} 0 ;(1) \mathrm{M} 1$ (2) Mx

\section{III- DADOS DO TRATAMENTO}

Cirurgia:

Data: Reconstrução: (0) não; (1) sim:

Complicações: (0) não; (1) Sim

Esvaziamento cervical: (0) não; (1) sim:

Radioterapia: (0) não; (1) sim

Local: (1) cérvicofacial; (2) fossas; (3) local; (4) cérvicofacial e local; (5) cérvicofacial e fossas

Data:

Dose:

Qt: (0) não; (1) sim

Ciclos:
Momento: (1) Indução, (2) concomitante à RT

Final do tratamento:

Via alternativa de alimentação: (0) não; (1) sim. Tipo: (1) SNG; (2) SNE; (3) Gastrostomia

Via oral: (1) líquido; (2) néctar; (3) mel; (4) pastoso; (5) sólido

TQT: (0) não; (1) sim. Tipo: (1) Plástica com cuff insuflado;

(2) Plástica com cuff desinflado; (3) Metálica.

Fonoterapia: (0) não; (1) sim

\section{IV - SINTOMAS}

Inchaço: (0) não; (1) sim

Sensação de peso: (0) não; (1) sim

Rigidez no pescoço e redução do movimento: (0) não; (1) sim

Alteração na aparência: (0) não; (1) sim

Dor: (0) não; (1) sim

Dificuldade para falar: (0) não; (1) sim

Dificuldade para engolir: (0) não; (1) sim 


\section{ANEXO D - Avaliação do edema e do linfedema de face e pescoço}

\section{Avaliação da Face}

(1) Circunferência facial

(a) Diagonal: mento à glabela

(b) Submentoniana: $<1 \mathrm{~cm}$ à frente da orelha, alinhamento vertical da fita

(2) Ponto a ponto

(a) Ângulo à ângulo da mandíbula -

(b) Trágus à trágus -

(c) Composição facial

(I) Trágus à protuberância mentoniana $D$ / E

(II) Trágus à comissura labial $D$ / $\mathrm{E}$

(III) Ângulo da mandíbula à asa nasal D / E

(IV) Ângulo da mandíbula ao canto interno do olho D /E

(V) Ângulo da mandíbula ao canto externo do olho D / $\mathrm{E}$

(VI) Protuberância mentoniana ao canto interno do olho D / E

(VII) Ângulo da mandíbula à protuberância mentoniana D / E

\section{Circunferências do pescoco}

(A) Superior: imediatamente abaixo da mandíbula

(B) Medial: porção média entre a superior e inferior

(C) Inferior: Porção mais baixa

Quadro 1. Escala de linfedema em cabeça e pescoço do MDACC

\begin{tabular}{|l|l|}
\hline Níveis & Descrição \\
\hline 0 & Sem edema visível, mas o paciente relata peso \\
\hline $1^{\text {a }}$ & Edema leve visível: sem depressão, reversível \\
\hline $1 b$ & Edema com depressão leve; reversível \\
\hline 2 & Edema com depressão firme; irreversível; sem alteração dos tecidos \\
\hline 3 & Edema irreversível; alterações dos tecidos \\
\hline
\end{tabular}

Local do edema: Face: (0) não; (1) sim Grau

Pescoço: (0) não; (1) sim Grau

Submandibular: (0) não; (1) sim Grau 
ANEXO E - Avaliação do edema interno de faringe e laringe

Quadro 2. Escala do edema da radioterapia

\begin{tabular}{|l|l|l|l|l|}
\hline & \multicolumn{3}{|c|}{ Classificação do edema } \\
\hline Estruturas & Normal & Discreto & Moderado & Severo \\
\hline Base da língua & & & & \\
\hline $\begin{array}{l}\text { Parede posterior de } \\
\text { faringe }\end{array}$ & & & & \\
\hline Epiglote & & & & \\
\hline $\begin{array}{l}\text { Pregas faringo- } \\
\text { epiglóticas }\end{array}$ & & & & \\
\hline Pregas ariepiglóticas & & & & \\
\hline Espaço interaritenóideo & & & & \\
\hline Área retrocricóidea & & & & \\
\hline Aritenóides & & & Moderadamente & Severamente \\
Pregas vestibulares & & & & \\
\hline Pregas vocais & & & & \\
\hline Comissura anterior & & & & \\
\hline Espaços & & & & \\
\hline Valécula & & & & \\
\hline Seios piriformes & & & & \\
\hline
\end{tabular}




\section{ANEXO F - Escala de avaliação de penetração, aspiração e resíduo faríngeo}

Quadro 3. Escala de penetração e aspiração

\begin{tabular}{|l|l|}
\hline NÍVEL & DESCRIÇÃO \\
\hline 1 & Material não entra em via aérea \\
\hline 2 & $\begin{array}{l}\text { Material entra em via aérea, permanece acima das pregas vocais e é ejetado } \\
\text { pelo ar }\end{array}$ \\
\hline 3 & $\begin{array}{l}\text { Material entra em via aérea, permanece acima das pregas vocais com } \\
\text { resíduo visível e não é ejetado pelo ar }\end{array}$ \\
\hline 4 & $\begin{array}{l}\text { Material entra em via aérea, entra em contato com as pregas vocais e é } \\
\text { ejetado pelo ar }\end{array}$ \\
\hline 5 & $\begin{array}{l}\text { Material entra em via aérea, entra em contato com as pregas vocais e não é } \\
\text { ejetado pelo ar }\end{array}$ \\
\hline 6 & $\begin{array}{l}\text { Material entra em via aérea, passa entre as pregas vocais e é ejetado para } \\
\text { laringe ou para fora da via aérea }\end{array}$ \\
\hline 8 & $\begin{array}{l}\text { Material entra em via aérea, passa entre as pregas vocais e não é ejetado } \\
\text { para laringe ou para fora da via aérea apesar do esforço }\end{array}$ \\
\hline para ejetar o material
\end{tabular}

Quadro 4. Escala de 4 pontos de gravidade de resíduo faríngeo

\begin{tabular}{|l|l|}
\hline NÍVEL & DESCRIÇÃO \\
\hline 0 & Sem resíduo \\
\hline 1 & Cobertura de mucosa faríngea sem acúmulo \\
\hline 2 & Acúmulo ou resíduo discreto \\
\hline 3 & Acúmulo ou resíduo moderado \\
\hline 4 & Acúmulo ou resíduo grave \\
\hline
\end{tabular}


ANEXO G - Medidas da avaliação da face e pescoço

Tabela 2. Medidas da avaliação da face e pescoço.

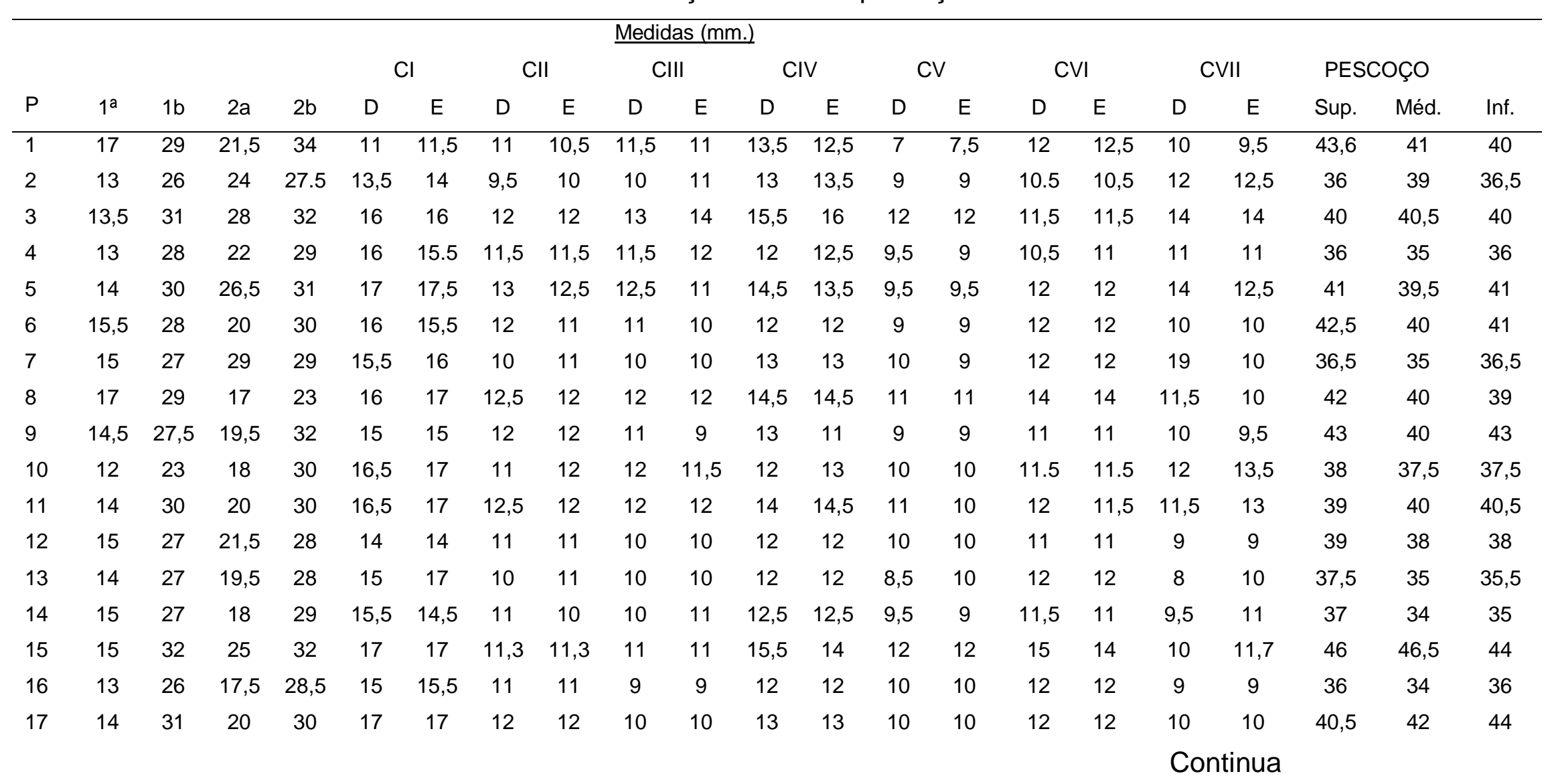


Tabela 2. Medidas da avaliação da face e pescoço.

continuação

\begin{tabular}{|c|c|c|c|c|c|c|c|c|c|c|c|c|c|c|c|c|c|c|c|c|c|}
\hline \multirow[b]{3}{*}{$\mathrm{P}$} & \multirow[b]{3}{*}{$1^{\underline{a}}$} & \multirow[b]{3}{*}{$1 b$} & \multirow[b]{3}{*}{$2 a$} & \multirow[b]{3}{*}{$2 b$} & \multicolumn{10}{|c|}{ Medidas (mm.) } & \multirow{2}{*}{\multicolumn{2}{|c|}{$\mathrm{CVI}$}} & \multirow{2}{*}{\multicolumn{2}{|c|}{ CVII }} & \multirow{2}{*}{\multicolumn{2}{|c|}{ PESCOÇO }} & \multirow[b]{3}{*}{ Inf. } \\
\hline & & & & & \multicolumn{2}{|c|}{$\mathrm{Cl}$} & \multicolumn{2}{|c|}{ Cll } & \multicolumn{2}{|c|}{ CIII } & \multicolumn{2}{|c|}{ CIV } & \multicolumn{2}{|c|}{$\mathrm{CV}$} & & & & & & & \\
\hline & & & & & $\mathrm{D}$ & $\mathrm{E}$ & D & $E$ & $\mathrm{D}$ & $\mathrm{E}$ & D & $E$ & D & $E$ & $\mathrm{D}$ & $\mathrm{E}$ & D & $E$ & Sup. & Méd. & \\
\hline 18 & 19 & 30 & 18 & 29 & 16 & 16 & 11 & 11 & 10 & 10 & 13 & 13 & 11 & 11 & 12 & 12 & 9 & 9 & 38,2 & 36 & 36,5 \\
\hline 19 & 15 & 31 & 23 & 30 & 15 & 15 & 10 & 10 & 10 & 10 & 12 & 12 & 10 & 10 & 13 & 13 & 9 & 9 & 40 & 39 & 40 \\
\hline 20 & 14 & 28 & 18,5 & 28 & 15 & 15 & 10 & 10 & 11 & 11 & 13 & 13 & 11 & 11 & 11 & 11 & 10 & 10 & 48 & 45 & 43 \\
\hline 21 & 14 & 29 & 22.5 & 29 & 15 & 15 & 10 & 10 & 10 & 10 & 12 & 13 & 10 & 10 & 12 & 12 & 10 & 12 & 41 & 39 & 41 \\
\hline 22 & 14 & 17 & 21 & 28 & 14 & 14 & 11 & 10 & 12 & 11 & 12 & 10 & 12,5 & 13 & 10 & 10 & 11 & 10 & 42 & 40 & 41 \\
\hline 23 & 15 & 30 & 21,5 & 29 & 16 & 16 & 11,5 & 11,2 & 10 & 10 & 12 & 12 & 10 & 9 & 12 & 13 & 12 & 11 & 45 & 44 & 42 \\
\hline 24 & 16 & 24 & 17 & 25 & 13 & 13 & 8 & 8 & 10 & 10 & 12 & 12 & 9 & 10 & 11 & 11 & 11 & 11 & 33 & 31 & 33 \\
\hline 25 & 25 & 23,5 & 13 & 23,5 & 12,5 & 13 & 9 & 9 & 9 & 9 & 11 & 10 & 9,5 & 9,5 & 11 & 11 & 9 & 9 & 34 & 32 & 32,5 \\
\hline 26 & 13,5 & 26 & 11,8 & 25 & 15 & 14 & 11 & 11 & 10 & 10 & 11 & 11 & 9 & 11 & 10 & 10 & 10 & 10 & 37,5 & 35 & 34 \\
\hline 27 & 16 & 17 & 18 & 27 & 14 & 15 & 11 & 11 & 12 & 11 & 14 & 14 & 11 & 10 & 12 & 12 & 11 & 12 & 43,5 & 39 & 39,5 \\
\hline 28 & 14 & 29 & 23,5 & 26 & 16 & 17 & 11 & 11 & 10 & 11 & 12 & 12 & 8 & 10 & 11 & 11 & 10 & 10 & 46 & 43,5 & 40 \\
\hline 29 & 16,2 & 28 & 20 & 26 & 13,5 & 14 & 13 & 10 & 9,5 & 10 & 13 & 13 & 9,5 & 10 & 14 & 13 & 10 & 10 & 44,5 & 41 & 40 \\
\hline 30 & 14 & 23 & 20 & 25 & 12 & 13 & 9 & 10 & 10 & 10 & 11 & 12 & 9 & 9 & 11 & 11 & 10 & 10 & 35,5 & 33 & 34,5 \\
\hline 31 & 17 & 27 & 23 & 26 & 14 & 14 & 9,5 & 9 & 11,5 & 11 & 13,5 & 14 & 10 & 7,5 & 13 & 13 & 12,5 & 13,3 & 42,5 & 39 & 39 \\
\hline 32 & 14 & 12 & 20 & 23,5 & 14 & 14 & 10 & 10 & 10 & 12 & 12 & 13 & 9 & 11,5 & 11,5 & 11,5 & 11 & 11 & 39 & 34 & 32 \\
\hline 33 & 16 & 30 & 21 & 29 & 16 & 18 & 11 & 12 & 13 & 13 & 15 & 18 & 10 & 12 & 14 & 13 & 11 & 13 & 48 & 46 & 46 \\
\hline 34 & 14 & 22 & 20 & 25 & 15 & 15 & 11 & 10 & 10 & 10 & 11,5 & 12,5 & 10 & 10 & 12 & 12 & 9 & 9 & 37 & 33 & 34 \\
\hline 35 & 17,5 & 32 & 23 & 28,5 & 17 & 17 & 12 & 12 & 13 & 12 & 14,5 & 14 & 9 & 10 & 14 & 14 & 12 & 14 & 48 & 48,5 & 48 \\
\hline 36 & 16 & 30 & 26 & 27 & 13 & 14 & 9 & 10 & 10 & 12 & 13,5 & 12 & 9 & 11 & 12 & 12 & 12 & 10 & 41 & 40 & 40 \\
\hline 37 & 14 & 24 & 21 & 24 & 14 & 14 & 10 & 10 & 10 & 10 & 10 & 10 & 12 & 11 & 11 & 11 & 11 & 11 & 39 & 34 & 35 \\
\hline 38 & 15 & 29 & 24 & 28,5 & 15 & 17 & 10 & 10 & 11 & 12 & 12 & 14 & 11 & 11 & 13 & 12 & 12 & 12 & 37,5 & 36 & 38 \\
\hline 39 & 16,5 & 26 & 23 & 28 & 16 & 15 & 10 & 10 & 12 & 12 & 11 & 11 & 10 & 10 & 12 & 12 & 12 & 12 & 41 & 39 & 41 \\
\hline
\end{tabular}


Tabela 2. Medidas da avaliação da face e pescoço.

conclusão

\begin{tabular}{|c|c|c|c|c|c|c|c|c|c|c|c|c|c|c|c|c|c|c|c|c|c|}
\hline \multirow[b]{3}{*}{$\mathrm{P}$} & \multirow[b]{3}{*}{$1^{a}$} & \multirow[b]{3}{*}{$1 b$} & \multirow[b]{3}{*}{$2 a$} & \multirow[b]{3}{*}{$2 b$} & \multicolumn{10}{|c|}{ Medidas (mm.) } & & & & & & & \\
\hline & & & & & \multicolumn{2}{|c|}{$\mathrm{Cl}$} & \multicolumn{2}{|c|}{ Cll } & \multicolumn{2}{|c|}{ CIII } & \multicolumn{2}{|c|}{ CIV } & \multicolumn{2}{|c|}{$\mathrm{CV}$} & \multicolumn{2}{|c|}{ CVI } & \multicolumn{2}{|c|}{ CVII } & \multicolumn{2}{|c|}{ PESCOÇO } & \multirow[b]{2}{*}{ Inf. } \\
\hline & & & & & $\mathrm{D}$ & $E$ & $D$ & $E$ & $\mathrm{D}$ & $\mathrm{E}$ & $\mathrm{D}$ & $E$ & $\mathrm{D}$ & $E$ & $\mathrm{D}$ & $E$ & $D$ & $\mathrm{E}$ & Sup. & Méd. & \\
\hline 40 & 13,5 & 27 & 23,5 & 23,5 & 14 & 13 & 10 & 8 & 8 & 10 & 12 & 12 & 10 & 10 & 11 & 11 & 12 & 12 & 37 & 35 & 36 \\
\hline 41 & 14 & 24 & 20 & 24 & 13 & 13 & 8 & 9 & 10 & 11 & 12 & 13 & 9 & 10 & 12 & 11 & 10 & 10 & 30 & 31 & 32 \\
\hline 42 & 14 & 24 & 20 & 23 & 12 & 12 & 8 & 8 & 9 & 8 & 11 & 10 & 8 & 9 & 10 & 10 & 10 & 10 & 40 & 38 & 40 \\
\hline 43 & 14,5 & 27,5 & 23 & 24 & 14 & 14 & 10 & 10 & 10 & 11 & 10 & 12 & 10 & 12 & 12 & 12 & 12 & 11 & 43 & 42 & 37 \\
\hline 45 & 15 & 23 & 20,5 & 23 & 13 & 13 & 9 & 9 & 10 & 10 & 13 & 13 & 9 & 9 & 12,5 & 12,5 & 12,5 & 12,5 & 32 & 33 & 32 \\
\hline 46 & 18 & 26 & 22 & 24,5 & 13 & 14,5 & 8 & 8 & 9 & 9 & 10 & 10 & 10 & 9 & 12 & 12,5 & 12 & 12 & 36 & 33 & 33 \\
\hline
\end{tabular}

Legenda: mm: milímetros; P:pacientes; 1a Diagonal: mento à glabela; 1b Submentoniana: <1 cm à frente da orelha, alinhamento vertical da fita; 2a: Ângulo à ângulo da mandíbula; 2b: Trágus à trágus; Cl: Trágus à protuberância mentoniana; CII: Trágus à comissura labial;CIII: Ângulo da mandíbula à asa nasal; CIV: Ângulo da mandíbula ao canto interno do olho; CV: Ângulo da mandíbula ao canto externo do olho; CVI: Protuberância mentoniana ao canto interno do olho; CVII Ângulo da mandíbula à protuberância mentoniana; D: direita; E: esquerda; Pescoço:

Sup.:superior; Méd.: médio; Inf.: inferior. 
9 REFERÊNCIAS BIBLIOGRÁFICAS 



\section{REFERÊNCIAS BIBLIOGRÁFICAS}

1- Posner MR. Integrating systemic agents into multimodality treatment of locally advanced head and neck cancer. Ann Oncol. 2010;21:245-51.

2- Bentzen SM, Dörr W, Anscher MS, Denham JW, Hauer-Jensen M, Marks LB, Williams J. Normal tissue effects: reporting and analysis. Semin Radiat Oncol. 2003;13:189-202.

3- Thomas L, Jones TM, Tandon S, Carding P, Lowe D, Rogers S. Speech and voice outcomes in oropharyngeal cancer and evaluation of the University of Washington quality of life speech domain. Clin Otolaryngol. 2009;34:34-42.

4- Lin E, Hwang TZ, Hornibrook J, Ormond T. Voice of postradiotherapy nasopharyngeal carcinoma patients: Evidence of vocal cord tract effect. J Voice. 2008;22:351-64.

5 - Murphy BA, Gilbert J, Ridner SH. Systemic and global toxicities of head and neck treatment. Expert Rev Anticancer Ther. 2007;7:1043-53.

6- Ahlberg A, Nikolaidis P, Engström T, Gunnarsson K, Johansson H, Sharp L et al. Morbidity of supraomohyoidal and modified radical neck dissection combined with radiotherapy for head and neck cancer: a prospective longitudinal study. Head Neck. 2012;34:66-72.

7- Barros APB, Portas JG, Queija DS, Lehn CN. Qualidade de vida relacionada à deglutição e índice de desvantagem vocal após tratamento para o câncer oral e de orofaringe. Rev Bras Cabeça Pescoço. 2006;35:147-51.

8- Tabibiazar R, Cheung L, Han J, Swanson J, Beilhack A, An A, Dadras SS, Rockson N, Joshi S, Wagner R, Rockson SG. Inflammatory 
manifestations of experimental lymphatic insufficiency. PLoS Med 2006;3:e254.

9- Deng J, Ridner SH, Dietrich MS, Wells N, Wallston KA, Sinard RJ, Cmelak AJ, Murphy BA. Factors associated with external and internal lymphedema in patients with head and neck cancer. Int J Radiation Oncol Biol Phys. 2012;84:319-28.

10- McGarvey AC, Osmotherly PG, Hoffman GR, Chiarelli PE. Lymphoedema following treatment for head and neck cancer: impact on patients, and beliefs of health professional. Eur J Cancer Care. 2014;23:317-27.

11- Sagili S, Dinesh S, Malhotra R. Eyelid lymphedema following neck dissection and radiotherapy. Ophthal Plast Reconstr Surg. 2013;29:e146-9.

12-Deng J, Ridner SH, Wells N, Dietrich MS, Murphy BA. Development and preliminary testing of head and neck cancer related external lymphedema and fibrosis assessment criteria. Eur J Oncol Nurs. 2015;19(1):75-80.

13- Stout Gergich NL, Pfalzer LA, McGarvey C, Springer B, Gerber LH, Soballe P. Preoperative assessment enables the early diagnosis and successful treatment of lymphedema. Cancer. 2008;112(12):2809-19.

14- Deng J, Ridner SH, Aulino JM, Murphy BA. Assessment and measurement of head and neck lymphedema: State-of-the-science and future directions. Oral Oncol. 2015;51:431-7.

15- Deng J, Ridner SH, Dietrich MS, Wells N, Wallston, KA, Sinard RJ, Cmelak AJ, Murphy BA. Prevalence of Secondary Lymphedema in Patients With Head and Neck Cancer. J Pain Symptom Man. 2012;43(2):244-52.

16- Deng J, Murphy BA, Dietrich MS, Wells N, Wallston KA, Sinard RJ, Cmelak AJ, Gilbert J, Ridner SH. Impact of secondary lymphedema after head and 
neck cancer treatment on symptoms, functional status, and quality of life. Head Neck. 2013;35(7):1026-35.

17- Deng J, Murphy BA, Dietrich MS, Sinard RJ, Mannion K, Ridner SH. Differences of symptoms in head and neck cancer patients with and without lymphedema. Support Care Cancer.2016;24:1305-16.

18-Smith BG, Hutcheson KA, Little LG, Skoracki RJ, Rosenthal DI, Lai SY, Lewin JS. Lymphedema outcomes in patients with head and neck cancer. Otolaryngol Head Neck Surg. 2015;152(2):284-91.

19-Smith BG, Lewin JS. Lymphedema management in head and neck cancer. Curr Opin Otolaryngol Head Neck Surg. 2010;18:153-8.

20-Deng J, Ridner SH, Dietrich MS, Wells N, Murphy BA. Assessment of external lymphedema in patients with head and neck cancer: A comparison of four scales. Oncol Nurs Forum. 2013;40(5):501-6.

21-Deng J, Dietrich MS, Ridner SH, Fleischer AC, Wells N, Murphy BA. Preliminary evaluation of reliability and validity of head and neck external lymphedema and fibrosis assessment criteria. Eur $\mathrm{J}$ Oncol Nurs. 2016;22:63-70.

22- Lymphoedema framework. Best practice for the management of lymphoedema. International consensus. London: MEP; 2006.

23-Patterson JM, Hildreth A, Wilson JA. Measuring edema in irradiated head and neck cancer patients. Ann Otol Rhinol Laryngol. 2007;116(8):559-64.

24-Queija DS, Arakawa-Sugueno L, Chamma BM, Kulcsar MA, Dedivitis RA. Tradução e adaptação para o português brasileiro da Lymphedema Rating Scale in Head and Neck Cancer. Einstein. 2017;15(4):457-64. 
25-Queija DS, Arakawa-Sugueno L, Chamma BM, Kulcsar MA, Dedivitis RA. Translation and adaptation of the Radiotherapy Edema Rating Scale to Brazilian Portuguese. Braz J Otorhinolaryngol. 2018;84(3):344-350.

26-Prince MEP, Ailles LE. Cancer stem cells in head and neck squamous cell cancer. J Clin Oncol. 2008;26(17):2871-5.

27-Ministério da Saúde. Instituto Nacional do Câncer. [homepage da internet] Estimativa 2016. Incidência de câncer no Brasil. http://www.inca.gov.br/estimativa/2016/sintese-de-resultadoscomentarios.asp. Acessado em 05/02/2017.

28-Verlag S.(Org.). Manual de oncologia clínica. 6aㅗ ed. São Paulo: Fundação Oncocentro de São Paulo; 1999.pp.270-89.

29-Kowalski LP. Câncer de Cabeça e Pescoço. In: Carrara-de Angelis E, Furia CLB, Mourão LF, Kowalski LP. A atuação da fonoaudiologia no câncer de cabeça e pescoco. São Paulo: Lovise; 2000.p.23.

30-Pignon JP, Bourhis J, Domenge C, Designé L. Chemotherapy added to locoregional treatment for head and neck squamous cell carcinoma: three meta-analyses of updated individual data. MACH-NC Collaborative Group. Meta-analysis of chemotherapy in head and neck cancer. Lancet. 2000;355:949-55.

31-Pignon JP, Le Maitre A, Maillard E, Bourhis J. MACH-NC Collaborative Group. Meta-analysis of chemotherapy in head and neck cancer (MACHNC): an update of 93 trials and 17, 346 patients. Radiother Oncol. 2009;92:4-14.

32-Forastiere AA, Goepfert H, Maor M, Pajak TF, Weber R, Morrison W, Glisson B, Trotti A, Ridge JA, Chao C, Peters G, Lee DJ, Leaf A, Ensley J, 
Cooper J. Concurrent chemotherapy and radiotherapy for organ preservation in advanced laryngeal cancer. N Engl J Med. 2003;349:2091-8.

33-Colasanto JM, Prasad P, Nash MA, Decker RH, Wilson LD. Nutritional support of patients Undergoing radiation therapy for head and neck cancer. Oncology. 2005;19(3):371-9.

34-Truong MT, Lee R, Saito N, Qureshi MM, Ozonoff A, Romesser PB, Wang J, Sakai O. Correlating computed tomography perfusion changes in the pharyngeal constrictor muscels during radiotherapy to dysphagia outcome. Int. J. Radiation Oncology Biol Phys. 2012;82(2):119-27.

35-Tedla M, Valach M, Carrau RL, Varga I, Profant M, Mráz P, Weismann P. Impact of radiotherapy on laryngeal intrinsic muscles. Eur Arch Otorhinolaryngol. 2012;269(3):953-8.

36-Fenwick JD, Pardo-Montero J, Nahum AE, Malik ZI. Impact of schedule duration on head and neck radiotherapy: accelerated tumor repopulation versus compensatory mucosal proliferation. Int J Radiat Oncol Biol Phys. 2012;82(2):1021-30.

37-Peters LJ, Ang KK, Thames HD Jr. Accelerated fractionation in the radiation treatment of head and neck cancer. A critical comparison of different strategies. Acta Oncol. 1988;27(2):185-94.

38-Kowalski LP, Sanabria A. Elective neck dissection on oral carcinoma: a critical review of the evidence. Acta Othorhinolaryngol Ital. 2007;27:113-7.

39- Tacani PM, Santos APR, Poscolere DD, Padilha QCSV, Amatu TKI, Montezello D, Pereira JF, Góes JCGS. Protocolo de avaliação de linfedema de cabeça e pescoço. Rev Bras Cir Cabeça Pescoço. 2010;39( 2):126-30. 
40-Nouraei SAR, Upile T, Al-Yaghchi C, Lei M, Sandhu GS, Stewart S, Clarke PM, Sandison A. Role of planned postchemoradiotherapy selective neck dissection in the multimodality management of head and neck cancer. Laryngoscope. 2008;118:797-803.

41-Frank DK, Hu KS, Culliney BE, Persky MS, Nussbaum M, Schantz SP, Malamud SC, Holliday RA, Khorsandi AS, Sessions RB, Harrison LB. Planned neck dissection after concomitant radiochemotherapy for advanced head and neck cancer. Laryngoscope. 2005;115(6):1015-20.

42- Carr SD, Bowyer D, Cox G. Upper limb dysfunction following selective neck dissection: a retrospective questionnaire study. Head Neck. 2009;31:78992.

43- van Wouwe M, de Bree R, Kuik DJ, et al. Shoulder morbidity after nonsurgical treatment of the neck. Radiother Oncol. 2009;90:196-201.

44- van Wilgen CP, Dijkstra PU, van der Laan BF, Plukker JT, Roodenburg JL. Shoulder and neck morbidity in quality of life after surgery for head and neck cancer. Head Neck. 2004;26:839-44.

45- Kuntz AL, Weymuller EA Jr. Impact of neck dissection on quality of life. Laryngoscope. 1999;109:1334-8.

46- Rogers SN, Ferlito A, Pellitteri PK, Shaha AR, Rinaldo A. Quality of life following neck dissections. Acta Otolaryngol. 2004;124:231-6.

47- van Wilgen CP, Dijkstra PU, van der Laan BF, Plukker JT, Roodenburg JL. Morbidity of the neck after head and neck cancer therapy. Head Neck. 2004;26:785-91. 
48- Hirai H, Omura K, Harada H, Tohara H. Sequential evaluation of swallowing function in patients with unilateral neck dissection. Head Neck. 2010;32:896-904.

49- Schiefke F, Akdemir M, Weber A, Akdemir D, Singer S, Frerich B. Function, postoperative morbidity, and quality of life after cervical sentinel node biopsy and after selective neck dissection. Head Neck. 2009;31:503-12.

50-Dorr W, Hendry JH: Consequential late effects in normal tissues. Radiother Oncol. 2001;61:223-31.

51- Portas JG. Ensaio clínico randomizado: intervenção fonoaudiologica na deglutição durante a radio-quimioterapia em pacientes com tumor de cabeça e pescoco. Tese (Doutorado). Barretos: Hospital de Câncer de Barretos; 2015.

52- Starmer HH, Gourin CG, Lua LL,Burkhead L. Pretreatment swallowing assessment in head and neck cancer patients. Laryngoscope. 2011;121:1208-11.

53- Lazarus CL, Husaini H, Hu K, Culliney B, Li Z, Urken M, Jacobson A, Persky M, Tran T, Concert C, Palacios D, Metcalfe-Klaw R. Kumar M, Bennett B, Harrison L. Functional outcomes and quality of life after chemoradiotherapy: baseline and 3 and 6 months post-treatment. Dysphagia. 2014;29(3):365-75.

54- Timme DW, Jonnaladadda $S$, Patel $R$, Rao K, Robbins KT. Treatment selection for T3/T4a laryngeal cancer: Chemoradiation versus primary surgery. Ann Otol Rhinol Laryngol. 2015;124(11):845-51.

55-Kotz T, Federman AD, Kao J, Milman L, Packer S, Lopez-Prieto C, Forsythe K, Genden EM. Prophylactic swallowing exercises in patients with head and 
neck cancer undergoing chemoradiation. Arch Otolaryngol Head Neck Surg. 2012;138(4):376-82.

56-Silveira MH, Dedivitis RA, Queija DS, Nascimento PC. Quality of life in swallowing disorders after nonsurgical treatment for head and neck cancer. Int Arch Otorhinolaryngol. 2015;19:46-54.

57-Portas J, Socci CP. Scian EP, Queija DS, Ferreira AS, Dedivitis RA, Barros APB. Swallowing after non-surgical treatment (radiation therapy/radiochemotherapy protocol)of laryngeal cancer. Braz $J$ Otorhinolaryngol.2011:77(1):96-101.

58-Lazarus CL. Effects of chemoradiotherapy on voice and swallowing. Curr Opin Otolaryngol Head Neck Surg. 2009;17(3):172-8.

59-Queija DS, Portas JG, Dedivitis RA, Lehn CN, Barros APB. Swallowing and quality of life after total laryngectomy and pharyngolaryngectomy. Braz $\mathrm{J}$ Otorhinolaryngol. 2009;75(4):556-64.

60-Queija DS, Ferreira AS, Portas JG, Dedivitis RA, PfuetzenreiterEG, Bohn NP, Barros APB. Avaliação vocal e auto-percepção da desvantagem vocal (VHI) após laringectomia fronto-lateral. Rev Bras Cir Cabeça Pescoço. 2007;36(2):95-9.

61-Portas JG, Queija DS, Arine LP, Ferreira AS, Dedivitis RA, Lehn CN, Barros APB. Voice and swallowing disorders: Functional results and quality of life following supracricoid laryngectomy with cricohyoidoepiglottopexy. Ear Nose Throat J. 2009; 88(10)E23-30.

62- Dedivitis RA, Queija DS, Barros APB, Pfu etzenreiter EG, Felippu A, Salvia VF, Gouveia Filho LF, Nishimoto IN.The Impact of the Glottic Configuration 
After Frontolateral Laryngectomy on the Perceptual Voice Analysis: A Preliminary Study. J Voice. 2008;22(6):760-4.

63- Majchrzak E, Szybiak B, Wegner A, Pienkowski P, Pazdrowski J, Luczewski L, Sowka M, Golusinski P, Malicki J, Golusinski W. Oral cavity and oropharyngeal squamous cell carcinoma in young adults: a review of the literature. Radiol Oncol. 2014;48(1):1-10.

64- Rockson SG, Rivera KK. Estimating the population burden of lymphedema. Ann NY Acad Sci. 2008;1131(1):147-54.

65- Murphy BA, Gilbert J. Dysphagia in head and neck cancer patients treated with radiation: assessment, sequelae, and rehabilitation. Semin Radiat Oncol. 2009;19(1):35-42.

66- Murphy BA, Gilbert J, Cmelak A, Ridner SH. Symptom control issues and supportive care of patients with head and neck cancers. Clin Adv Hematol Oncol. 2007;5(10):807-22.

67- Nixon J, Purcell A, Fleming J, McCann A, Porceddu S. Pilot study of an assessment tool for measuring head and neck lymphoedema. $\mathrm{Br} \mathrm{J}$ Community Nurs. 2014;19S6-11.

68- Guyton AC. Hall JE. Os compartimentos dos líquidos corporais: líquidos extracelular e intracelular, instersticial e edema. In: Tratado de fisiologia médica. 10ª ed. Rio de Janeiro: Guanabara Koogan; 2002. pp.250-64.

69- Prim MP, De Diego JI, Madero R, Gavillan J. Status of internal jugular veins in patients with carcinomas of the head and neck área. Otolaryngol Head Neck Surg. 2004;131:494-6.

70- Chen MH, Chang PM, Chen PM, Tzeng CH, Chu PY, Chang SY, Yang MH. Prolonged facial edema is an indicator of poor prognosis in patients with 
head and neck squamous cell carcinoma. Support Care Cancer. 2010;18:1313-9.

71- Rockson SG, Rivera K.K. Estimating the population burden of lymphedema. Annals NY Acad Sci. 2008;1131:147-54.

72- Avraham T, Zampell JC, Yan A, Elhadad S, Weitman ES, Rockson SG, Bromberg J, Mehrara BJ. Th2 differentiation is necessary for soft tissue fibrosis and lymphatic dysfunction resulting from lymphedema. FASEB J. 2013;27(3):1114-26.

73- Mozzini CB. Edema na face e no pescoço após esvaziamento cervical com ou sem ressecção da veia jugular interna [tese]. São Paulo: Faculdade de Medicina da Universidade de São Paulo; 2011.

74- Földi MD, Földi E, Strössenreuther RHK., Kubik S. Földi's textbook of lymphology: For physicians and lymphedema therapists. $2^{\mathrm{a}}$ ed. Munich: Urban and Fischer; 2007.

75- Leduc A, Leduc O. Drenagem linfática: teoria e prática. 3aㅗ ed. Barueri: Manole; 2008.

76- S. Department of Health and Human Services, National Institutes of Health, National Cancer Institute. Common Terminology Criteria for Adverse Events v4.0 (CTCAE); 2010 [acessado: 24.02.2017]. Método de acesso: http://evs.nci.nih.gov/ftp1/CTCAE/CTCAE 4.03 2010-06-

\section{QuickReference 8.5x11.pdf}

77- American Cancer Society, Donaldson S. Lymphedema: understanding and managing lymphedema after cancer treatment. Atlanta: American Cancer Society; 2006. 
78- Purcell A, Nixon J, Fleming J, McCann A, Pordeddu S. Measuring Head and Neck Lymphoedema: The "ALOHA" Trial. Head Neck. 2016;38(1):7984.

79- Piso DU, Eckardt A, Liebermann A,Gutenbrunner C, Schäfer P. Gehrke A. Early rehabilitation of head-neck edema after curative surgery for orofacial tumors. Am J Phys Med Rehabil. 2001;80(4):261-9.

80- Arieiro EG, Machado KS, Lima VP, Tacani RE, Diz AM. A eficácia da drenagem linfática manual no pós-operatório de câncer de cabeça e pescoço. Rev Bras Cir Cabeça Pescoço. 2007;36(1):43-6.

81- Zimmermann T, Leonhardt $\mathrm{H}$, Kersting S, Albrecht S, Range U, Eckelt U. Reduction of postoperative lymphedema after oral tumor surgery with sodiu m selenite. Biol Trace Elem Res. 2005;106(3):193-203.

82- Patterson JM, Hildreth A, Wilson JA. Measuring edema in irradiated head and neck cancer patients. Ann Otol Rhinol Laryngol. 2007;116:559-64.

83- Buntzel J, Glatzel M, Mucke R, Micke O, Bruns F. Influence of amifostine on late radiationtoxicity in head and neck cancerda follow-up study. Anticancer Res. 2007;27:1953-56.

84- Wolff HA, Overbeck T, Roedel RM, Hermann RM, Herrmann MK, Kertesz T, Vorwerk H, Hille A, Matthias C, Hess CF, Christiansen H. Toxicity of daily low dose cisplatin in radiochemotherapy for locally advanced head and neck cancer. J Cancer Res Clin Oncol. 2009;135(7):961-7.

85- Ridner SH, Dietrich M S, Niermann, K, Cmelak A, Mannion K, Murphy B. A Prospective Study of the Lymphedema and Fibrosis Continuum in Patients with Head and Neck Cancer. Lymphat Res Biol. 2016;14(4):198-205. 
86- Jackson LK, Ridner SH, Deng J, Bartow C, Mannion K, Niermann K, Gilbert J, Dietrich MS, Cmelak AJ, Murphy BA. Internal lymphedema correlates with subjective and objective measures of dysphagia on head and neck cancer patients. J Paliat Med. 2016;19(9):949-56.

87- Rosenbek JC, Robbins J, Roecker EV, Coyle JL, Woods JL. A PenetrationAspiration Scale. Dysphagia. 1996;11:93-8.

88- Jung SH, k J, J H, Lee SU. Effect of the order of test diets on the accuracy and safety of swallowing studies. Ann Rehabil Med. 2014;38(3):304-9.

89- STATACorp. 2007. Stata Statistical Software: Release 10.0. College Station, Texas: Stata Corporation.

90- De Boer MF, McCormick LK, Pruyn JF, Ryckman RM, van den Borne BW. Physical and psychosocial correlates of head and neck cancer: a review of the literature. Otolaryngol Head Neck Surg. 1999;120:427-36.

91- Robbins KT, Kumar P, Regine WF, Wong FSH, Weir III AB, Flick P, Kun LE, Palmer R, Murry T, Fontanesi J, Ferguson R, Thomas R, Hartsel W, Paig CU, Salazar G, Norfleet L, Hanchetti CB, Harrington V, Niell HB. Efficacy of targeted supradose cisplatin and concomitant radiation therapy for advanced head and neck cancer: the Memphis experience. Int J Radiat Oncol Biol Phys.1997;38:263-71.

92- Rasmussen JC, Tan IC, Naqvi S, Aldrich MB, Maus EA, Blanco AI, Karni RJ, Sevick-Muraca EM. Longitudinal monitoring of the head and neck lymphatics in response to surgery and radiation. Head Neck. $2017 ; 39(6): 1177-1188$. 
93- Smith BG, Lewin JS. The role of lymphedema management in head and neck cancer. Curr Opin Otolaryngol Head Neck Surg. 2010;18(3):153-8.

94-Benninger MS, Alessi D, Archer S, Bastian R, Ford C, Koufman J, Sataloff RT, Spiegel JR, Woo P. Vocal fold scarring: current concepts and management. Otolaryngol Head Neck Surg.1996;115:474-82.

95- Lell M, Baum U, Greess $\mathrm{H}$, et al. Head and neck tumors: imaging recurrent tumor and post-therapeutic changes with CT and MRI. Eur J Radiol. 2000;33:239-47.

96- Remy J, Wegrowski J, Crechet F, Martin M, Daburon F. Long-term overproduction of collagen in radiation-induced fibrosis. Radiat Res 1991;125: 14-19.

97- Avraham T, Yan A, Zampell JC, Daluvoy SV, Haimovitz-Friedman A, Cordeiro AP, Mehrara BJ. Radiation therapy causes loss of dermal lymphatic vessels and interferes with lymphatic function by TGFbeta1mediated tissue fibrosis. Am J Physiol Cell Physiol.2010;299:C589-C605.

98- O'Sullivan B, Levin W. Late radiation-related fibrosis: pathogenesis, manifestations, and current management. Semin Radiat Oncol.2003;13:27489.

99- Delanian S, Lefaix JL. Current management for late normal tissue injury: radiation-induced fibrosis and necrosis. Semin Radiat Oncol.2007;17:99107.

100- Delanian S, Lefaix JL. The radiation-induced fibroatrophic process: therapeutic perspective via the antioxidant pathway. Radiother Oncol. 2004;73: 119-31. 
101- Delanian S, Lefaix JL, Pradal PF. Radiation-induced neuropathy in câncer survivors. Radiother Oncol.2012;105:273-82.

102- Stubblefield MD. Clinical evaluation and Management of Radiation Fibrosis Syndrome. Phys Med Rehabil Clin N Am.2017,28(1):89-100.

103- Meyer TK, Pisegna JM, Krisciunas GP, Pauloski BR, Langmore SE. Residue Influences Quality of Life Independently of Penetration and Aspiration in Head and Neck Cancer Survivor. Laryngoscope.2017;127(7):1615,21. 


\section{APÊNDICE}

Radiotherapy Edema Rating Scale ${ }^{23}$

\begin{tabular}{|l|l|l|l|l|}
\hline \multicolumn{2}{|l|}{} & \multicolumn{3}{l}{ Rating of edema } \\
\hline Structures & Normal & Mild & Moderate & \\
\hline Base of tongue & & & & \\
\hline Posterior pharyngeal wall & & & & \\
\hline Epiglottis & & & & \\
\hline Pharyngoepiglottic folds & & & & \\
\hline Aryepiglottic folds & & & & \\
\hline Interarytenoid space & & & & \\
\hline Cricopharyngeal prominence & & & & \\
\hline Arytenoids & & & & \\
\hline False vocal folds & & & & \\
\hline True vocal folds & & Mildly reduced & Moderately reduced & Severely reduced \\
\hline Anterior comissure & Normal & & & \\
\hline Spaces & & & & \\
\hline Valleculae & & & & \\
\hline Pyriform sinus & & & & \\
\hline
\end{tabular}

